\title{
STRATEGIC INTERACTIONS AND PRICE DYNAMICS IN THE GLOBAL OIL MARKET
}

2020

\section{BANCODEESPAÑA}

Eurosistema

Documentos de Trabajo

N. ${ }^{\circ} 2006$

Irma Alonso Álvarez, Virginia Di Nino and Fabrizio Venditti 
STRATEGIC INTERACTIONS AND PRICE DYNAMICS IN THE GLOBAL

OIL MARKET 
STRATEGIC INTERACTIONS AND PRICE DYNAMICS

IN THE GLOBAL OIL MARKET ${ }^{*}$

Irma Alonso Álvarez

BANCO DE ESPAÑA

Virginia Di Nino and Fabrizio Venditti

EUROPEAN CENTRAL BANK

$\left(^{*}\right)$ We would like to thank participants at ECB internal seminars and at the 2018 ISCEF conference. We are indebted to James Hamilton, Christiane Baumeister and Lutz Kilian for useful discussions. The views expressed in the paper are those of the authors and do not necessarily reflect those of the ECB, of the Banco de España or of the ESCB.

Documentos de Trabajo. N. ${ }^{\circ} 2006$

2020 
The Working Paper Series seeks to disseminate original research in economics and finance. All papers have been anonymously refereed. By publishing these papers, the Banco de España aims to contribute to economic analysis and, in particular, to knowledge of the Spanish economy and its international environment.

The opinions and analyses in the Working Paper Series are the responsibility of the authors and, therefore, do not necessarily coincide with those of the Banco de España or the Eurosystem.

The Banco de España disseminates its main reports and most of its publications via the Internet at the following website: http://www.bde.es.

Reproduction for educational and non-commercial purposes is permitted provided that the source is acknowledged.

C BANCO DE ESPAÑA, Madrid, 2020

ISSN: 1579-8666 (on line) 


\section{Abstract}

In a simplied theoretical framework, we model the strategic interactions between OPEC and non-OPEC producers and the implications for the global oil market. Depending on market conditions, OPEC may find it optimal to act either as a monopolist on the residual demand curve, to move supply in-tandem with non-OPEC, or to offset changes in non-OPEC supply. We evaluate the implications of the model through a Structural Vector Auto Regression (VAR) that separates non-OPEC and OPEC production and allows OPEC to respond to supply increases in non-OPEC countries. This is done by either increasing production (Market Share Targeting) or by reducing it (Price Targeting). We find that Price Targeting shocks absorb half of the fluctuations in oil prices, which have left unexplained by a simpler model (where strategic interactions are not taken into account). Price Targeting shocks, ignored by previous studies, explain around 10 percent of oil price fluctuations and are particularly relevant in the commodity price boom of the 2000s. We confirm that the fall in oil prices at the end of 2014 was triggered by an attempt of OPEC to re-gain market shares. We also find the OPEC elasticity of supply three times as high as that of non-OPEC producers.

Keywords: OPEC, shale, oil, VAR.

JEL classification: Q41, Q43. 


\section{Resumen}

En un marco teórico simplificado, modelizamos las interacciones estratégicas entre los productores de la OPEP y los no pertenecientes a la OPEP y sus implicaciones para el mercado global de petróleo. Dependiendo de las condiciones del mercado, la OPEP puede considerar óptimo actuar como monopolista en la curva de demanda residual, variar su oferta en tándem con los no miembros de la OPEP, o compensar los cambios en la oferta de los productores fuera de la OPEP. Evaluamos las implicaciones del modelo a través de un modelo autorregresivo estructural (SVAR) que distingue entre producción de los países no pertenecientes a la OPEP y producción de la OPEP, y permite que la OPEP responda a aumentos de la oferta de los países no-OPEP. Esto se hace ya sea aumentando la producción (Market Share Targeting) o reduciéndola (Price Targeting). Comprobamos que los shocks de Price Targeting absorben la mitad de las fluctuaciones de los precios del petróleo, que no han sido explicadas por modelos más sencillos (que no incorporan las interacciones estratégicas entre OPEP y no-OPEP). Los shocks de Price Targeting, ignorados por estudios anteriores, explican alrededor del $10 \%$ de las fluctuaciones de los precios del petróleo y son especialmente relevantes durante el auge de los precios de las materias primas en la década de 2000. Confirmamos que la caída de los precios del petróleo a finales de 2014 fue provocada por un intento de la OPEP de recuperar cuotas de mercado. También encontramos que la elasticidad de la oferta de la OPEP es tres veces mayor que la de los productores no pertenecientes a la OPEP.

Palabras clave: OPEP, shale, producción no convencional de petróleo, petróleo, VAR.

Códigos JEL: Q41, Q43. 


\section{Non-technical Summary}

Academics have long debated about the competitive structure of the global oil market and on the consequences for oil price formation. Existing studies have discussed whether OPEC is a cartel or a form of internal Stackelberg competition, to what extent members cooperate-coordinate their production strategies and the role of Saudi Arabia as the swing producer. More recently theoretical frameworks have considered the possibility that OPEC pursues different production strategies, depending on competitors' efficiency, production capacity and aggregate demand, in addition to internal OPEC cohesion.

We find the macro-empirical literature has somewhat disconnected from the debate, remaining anchored to the question of whether oil price fluctuations are dominated by unexpected changes in the supply of oil, or by shifts in global demand. In these studies, differences in the competitive environment of the global oil market play a limited role in guiding the identification of structural shocks. This is despite the acknowledgement that OPEC has the possibility and incentive (given the large market share and the production spare capacity) to act as a monopolist on the residual part of the demand curve. In recent years, the unprecedented surge in US shale oil production has radically changed market conditions, raising the question on whether this had an influence on oil price dynamics.

In this work we bridge the gap between theory and empirics, drawing a direct link between market structure and implications for structural empirical models of the global oil market. We show, in a simplified theoretical framework, how strategic interactions between a dominant player and fringe competitive firms can affect the oil market equilibrium. In particular the dominant player (OPEC) can operate alternative strategies, whereas fringe firms take as given market conditions and produce as much as their capacity allows. Specifically OPEC can act as a monopolist on the residual demand curve, and move its production in tandem with the production of the fringe firms (thereby following Market Share targeting). This is an attempt to keep market shares stable. Another option is to move production in the opposite direction to non-OPEC producers, thus attempting to stabilize prices around a target (Price Targeting). Next we ask to what extent these results can help our understanding of oil price dynamics in recent decades.

Following Kilian and Murphy (2014), we set up a Structural Vector Autoregressive Model (SVAR) of the global oil market in which we jointly model oil production, global economic activity, oil inventories and the price of oil. We modify the model in two directions to take into account the implications of our theoretical setup. First, we model OPEC and non-OPEC production separately. Second, we allow for distinct reactions from OPEC following a supply shock from non-OPEC countries. In the first case we let OPEC production move in the same direction as that of non-OPEC production. This identi- 
fication restriction coincides with the one employed by Kilian and Murphy (2014), Baumeister and Peersman (2013) and Baumeister and Hamilton (2019) to identify an oil supply shock. Consistently with our theoretical model, we define such shock a Market Share Targeting shock. In the second case we let OPEC production move in the opposite direction with respect to that of non-OPEC production, therefore stabilizing prices. We call this second shock a Price Targeting shock.

The main results of our empirical analysis are the following. First, Price Targeting shocks account for around 10 percent of the overall oil price forecast error variance on all horizons. They absorb around half of the forecast error variance that is left unexplained in a smaller model in which OPEC and non-OPEC production are not distinguished and only aggregate supply shocks are considered. Second, OPEC targeted prices, rather than market shares, in the early 2000s, somewhat contributed to booming oil prices in the run-up to the crisis. Third, we can characterize the supply elasticity for OPEC (0.20) to be notably higher than non-OPEC supply elasticity (0.06), on account of the OPEC's option to rapidly resort to spare capacity. Demand elasticity $(-0.28)$ is quantitatively in line with those obtained in recent studies (see Caldara, Cavallo, and Iacoviello (2019) and Baumeister and Hamilton (2019)). 


\section{Introduction}

Theoretical papers have long debated on the competitive structure of the global oil market and on the consequences for oil price formation. Existing studies have discussed whether OPEC is a cartel or a form of internal Stackelberg competition (Dahl (2004) and Berg, Kverndokk, and Rosendahl (1997)), to what extent members cooperate-coordinate their production strategies (Geroski, Ulph, and Ulph, 1987) and the role of Saudi Arabia as the swing producer (Nakov and Nuno, 2013). A more sophisticated approach is taken by Behar and Ritz (2017), who set up a model where OPEC can pursue alternative production strategies, depending on competitors' efficiency, production capacity and aggregate demand, in addition to internal OPEC cohesion. Some authors have also looked at how the market structure has evolved over time; Huppmann and Holz (2012b), for instance, argue that it has shifted from an oligopoly to a more competitive environment following the Great Recession.

The macro-empirical literature has remained somewhat disconnected from these studies and has focused on a relatively top-down question, i.e. whether oil price fluctuations are dominated by unexpected changes in the supply of oil or by shifts in global demand. In the early literature, supply factors were typically assumed to be the major drivers of oil prices. Little attention was paid to the underlying nature of oil price shocks and to their different macroeconomic effects. This view persisted until the end of the 2000s, when an increasing consensus identified global demand conditions as the key factor explaining oil price movements, especially in specific episodes like the run-up to the 2008 crisis, (see Kilian (2008), Kilian (2009), Kilian and Murphy (2014), Baumeister and Peersman (2013) and Baumeister and Hamilton (2015)). It is worth noticing that, in these studies, differences in the competitive environment of the global oil market play a limited role in guiding the identification of structural shocks. This is despite the acknowledgement that OPEC has the incentive and the ability (given their production spare capacity and their relatively large market share) to act as a monopolist on the residual part of the demand curve (Caldara, Cavallo, and Iacoviello, 2019). A loose relationship between market conditions and structural oil price drivers is implicitly drawn by Kilian and Murphy (2014), who assume oil supply elasticity to be relatively low. In recent years, the unprecedented surge in US shale oil production has radically changed market conditions, raising the question on whether this has had a influence on oil price dynamics (Foroni and Stracca (2019)), and its potential impact on Arab oil producers' economic policies (Kilian (2017)). ${ }^{1}$

While the focus in this work lies on an improved assessment of the contribution of OPECs strategy, and therefore of the contribution of supply shocks, to oil price fluctuations, a number of studies have

\footnotetext{
${ }^{1}$ The shale oil revolution has attracted significant interest because it has marked a historical and unexpected turning point in US energy production trends. After three decades of steady decline, US oil production provided the largest contribution to global supply growth in the period from 2012 to 2014 and today rivals Saudi Arabia and Russia in terms of its share in global oil production.
} 
instead investigated to what extent the activity of speculators in oil financial markets influences crude prices. Results are not univocal. Juvenal and Petrella (2015) encompass speculative shocks identified through a standard scheme of sign restrictions in a VAR model using factors extracted from a dynamic factor model. They find that speculative shocks start driving oil price upward in 2004, which is consistent with the timing when oil financial markets begun experiencing brisk investment inflows. They however confirm demand remains the dominant driver behind the oil price spike of 2008 . On the contrary Chari and Christiano (2017) using a large panel dataset containing information on multiple commodities find no significant empirical link between price behaviour and futures market trading. In the same vein, Fattouh and Mahadeva (2013) argue that there is no enough evidence to support a relevant role of speculation in driving oil prices in the run up to the global financial crisis. ${ }^{2}$

In this paper we contribute to the literature by drawing a direct link between strategic interactions in the oil market and its implications for structural empirical models of the global oil market. We start by presenting a simple theoretical framework that shows how strategic interactions can affect the oil market equilibrium. We consider a standard dominant firm-competitive fringe model for the crude oil market (see Golombek, Irarrazabal, and Ma (2018) among others). This environment is populated by fringe firms (shale producers for instance) that are atomistic, and one large player/producer (namely OPEC) that can exert market power and willingly influence the oil market equilibrium. In our setup, fringe firms take as given market conditions and supply as much as their capacity allows them to produce. OPEC, on the other hand, takes as given the production of the fringe firms and acts as a monopolist on the residual demand, strategically adjusting its production. However we depart from standard frameworks since in our model, depending on market conditions, OPEC can follow three strategies. Specifically it can operate as a monopolist on the residual demand curve, it can move its production in tandem with the production of the fringe firms, in an attempt to keep market shares stable. Alternatively it can modify the production in the opposite direction to non-OPEC producers, this time in an attempt to stabilize prices. Next we ask to what extent these results can help our understanding of oil price dynamics in recent decades.

This empirical strategy seems to be underpinned by the time-varying correlation between OPEC and non-OPEC supply. The developments of the correlation of OPEC and non-OPEC supply across time may reflect changes in the modus operandi of OPEC. In particular, Figure 1 shows the two strategies pursued by OPEC in the aftermath of the emergence of US shale production: its Price Targeting strategy and the switch from Price to Market Share Targeting in September 2014. Both policies are indicated by the red dotted vertical bars. We interpret the chart through the lenses of our theoretical underpinnings.

\footnotetext{
${ }^{2}$ Another question is the relation between oil prices and stock markets. For an extensive and interesting survey on this topic, see Degiannakis, Filis, and Arora (2018)
} 
Figure 1: Time varying correlation between OPEC and non OPEC supply

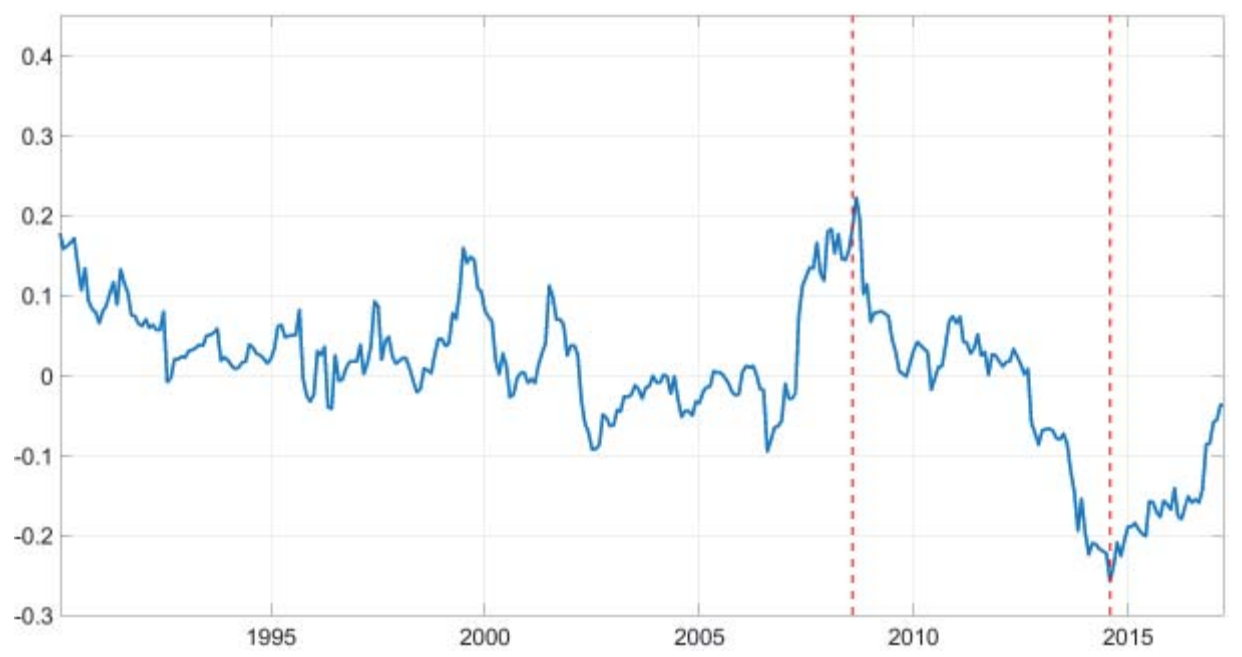

Notes: 60-month moving windows correlation between OPEC and non OPEC supply.

Until the start of the commodity super-cycle in early 2000, OPEC appears to have acted mainly as a monopolist on the residual demand. A modest positive correlation between OPEC and non-OPEC production suggests that higher global consumption was met gradually at increasing crude oil prices. But, the price spiral during the super-cycle period was also the result of OPEC manipulating global supply to maintain quotations rather high (since the correlation falls below zero). If we exclude the peak of the global financial crisis ( when this correlation was mainly driven by demand forces), the Price Targeting strategy was pursued until 2014. Indeed in the first stage of the shale age (from 2010 until the third quarter of 2014) OPEC kept restraining its own production as shale supply kept expanding unabated. ${ }^{3}$ Over this period, the correlation between OPEC and non OPEC supply remained below zero, exactly as predicted by the Price Targeting strategy in our model. Since then, OPEC has been mainly worried about defending its market share. In a world of declining production costs, as we explain in details in section 2 , the attempt of the dominant player to fix a price is doomed to fail. Indeed we believe a trigger of the switch in OPEC's production strategy was the persistent upward revision of the medium and long-term profile of shale production and reserves in mid-2014. From the end of 2014 the correlation reverts to a positive trend.

Following Kilian and Murphy (2014), we set up a Structural Vector Autoregressive Model (SVAR) of the global oil market in which we jointly model oil production, global economic activity, oil inventories and the price of oil. We modify the model in two directions to take into account the implications of our theoretical setup. First, we model OPEC and non-OPEC production separately. Second, we allow for distinct reactions of OPEC following a supply shock from non-OPEC countries. In the first

\footnotetext{
${ }^{3}$ This is documented in monthly oil bulletins by the increasing spare capacity of the cartel joint with a reduced supply
} 
case, we let OPEC production move in the same direction as that of non-OPEC production. This identification restriction coincides with the one employed by Kilian and Murphy (2014), Baumeister and Peersman (2013) and Baumeister and Hamilton (2019) to identify an oil supply shock. Consistently with our theoretical model, we define this shock as a Market Share Targeting shock. In the second case, we let OPEC production move in the opposite direction to that of non-OPEC production, therefore stabilizing prices. We call this second shock a Price Targeting shock. To the best of our knowledge, no previous work has so far quantified the implications for price developments of different OPEC's production strategies. In particular the literature has so far only considered one type of supply shock, overlooking the fact that in oligopolistic markets major producers can decide to compete over quantities or over prices.

The main results of our empirical analysis are the following. First, Price Targeting shocks account for around 10 percent of the overall oil price forecast error variance on all horizons. They absorb around half of the forecast error variance that is left unexplained in a smaller model in which OPEC and non-OPEC production are not distinguished and only aggregate supply shocks are considered. Second, OPEC targeted prices, rather than market shares, in the 2000s, somewhat contributed to booming oil prices in the run-up to the crisis. Third, we can characterize different supply elasticities for OPEC and non-OPEC producers. We estimate aggregate price elasticities of supply (0.10) and demand $(-0.28)$ that are quantitatively in line with those obtained in recent studies, see Caldara, Cavallo, and Iacoviello (2019) and Baumeister and Hamilton (2019). We estimate the price elasticity of OPEC supply to be around 0.2, similarly to (Caldara, Cavallo, and Iacoviello, 2019), and to be notably higher than that of non-OPEC suppliers (0.06). This difference is related to the OPEC's option to rapidly adapt production by resorting to spare capacity.

The remainder of the paper is organized as follows. In section 2, we provide a brief overview of the theoretical underpinnings behind the empirical identification strategy. Section 3 discusses the empirical strategy developed, highlighting the differences with previous known models. Section 4 presents the empirical results. Section 5 concludes.

\section{Theoretical framework}

In this section, we present a simple theoretical framework that accounts for strategic interactions of oil producers. This model will be used to assess under which conditions it is optimal for OPEC to switch from one strategy to another.

The oil market has traditionally been modeled as a special case of an imperfectly competitive market. While previous works suggest that oil players compete a la Cournot, or OPEC acts as a Stackelberg leader, Huppmann and Holz (2012a) show that the oil market structure has evolved 
over time, changing from an oligopoly to a more competitive framework after the Great Recession. Moreover, Hansen and Lindholt (2008) suggest that the characteristics of a dominant producer model can fit well the behaviour of OPEC after 1994.

As in Golombek, Irarrazabal, and Ma (2018), we consider a dominant firm-competitive fringe model for the crude oil market. We assume the existence of one large player/producer, namely OPEC, that can exert market power and influence the equilibrium. Nonetheless our theoretical framework departs from their model in a series of key features. Foremost our model encompasses three possible different types of behaviour of the dominant player. OPEC can play monopolist on the residual demand or act strategically adjusting its production in response to changes in the production of the fringe firms in order to either steer the equilibrium price or to make room for greater production. Unlike OPEC, the rest of producers, called fringe firms, (shale producers for instance) are atomistic, meaning that they take as given market conditions and stay ready to supply as much as their capacity allows them to produce. Therefore, non-OPEC producers are assumed to be price-takers. The different competitive behaviour between the dominant and the fringe firms is determined by the lower cost of production of the former, in this case OPEC. Furthermore the possibility for OPEC to pursue alternative strategies in our model depends on the assumption we hold about marginal costs of the two different types of players. Our model assumes constant marginal costs for OPEC and increasing marginal costs for non-OPEC.

In this framework, OPEC can act strategically since its production has an impact on the price of oil: if OPEC increases (decreases) its production, the price of oil will decrease (increase), caeteris paribus. Specifically OPEC can follow two different strategies as the marginal revenue has two sections in this model: it can charge a high price so both the dominant and the fringe firms make profits or break-even or it can set a low price such as the fringe firms are obliged to shut down to avoid making losses and the dominant firms becomes a monopoly. The decision will depend on OPEC's inter-temporal profit maximization problem, given by the following function:

$$
\Pi=\sum_{t=0}^{t=T} \beta^{t}\left[\left(p_{t}-c\right) Q_{O}\right]
$$

where $Q_{O}$ is OPEC's production, $p_{t}$ is the price of oil, $c$ is the constant marginal production cost and $\beta$ is the time discount factor. To keep the model as streamlined as possible, the demand schedule is assumed linear, a hypothesis that implies that the price elasticity of demand varies with $p$ and $Q$.

$$
p_{t}=a-b Q_{t}
$$

where $a$ and $b$ are parameters representing respectively market size and price sensitivity to change in quantities. $Q$ is the sum of OPEC and non-OPEC supply ( $Q_{O}$ and $Q_{N O}$ respectively). Non-OPEC 
operates at a unit production cost equal to $c_{N O}=\alpha c$ with $\alpha$ measuring the inefficiency relative to OPEC, which we assume to be strictly greater than 1.

Let's assume that OPEC sets a price higher than the marginal cost of the fringe firms $(p \geq \alpha c)$, so that all the firms make profits. From the maximization of OPEC's profit, subject to the residual demand constraint, we know that $Q_{O}$ can be expressed as a function of $Q_{N O}$ :

$$
Q_{O}=\frac{a-c}{2 b}-\frac{Q_{N O}}{2}
$$

and plugging back $Q_{O}$ in (2) also the price becomes a sole function of $Q_{N O}$ and parameters: ${ }^{4}$

$$
p=\frac{a+c}{2}-b \frac{Q_{N O}}{2}
$$

For a given demand, equation (3) shows that OPEC will restrain its supply following an increase in non-OPEC production, counteracting the initial shock in the attempt to stabilize the price. However it will accommodate only half of the variation $\left(\frac{\Delta Q_{N O}}{2}\right)$. As a result, total supply will increase and the price will fall but by less than in the case in which OPEC had not adjusted (by $\frac{b}{2} \Delta Q_{N O}$ in equation $(4))$.

Because non-OPEC producers are price-takers and cannot act strategically, they will produce as long as the oil market price remains above their production costs: $p \geq \alpha c$. In this case $Q_{N O}$ can be derived by imposing $p=\alpha c$ in 4 . The equilibrium supply of non-OPEC will be:

$$
Q_{N O}=\frac{a+(1-2 \alpha) c}{b}
$$

OPEC production is $Q_{O}=\frac{c(\alpha-1)}{b}$, a positive function of the profit margin. Notice however that, under a linear demand assumption, while non-OPEC increases its production in response to a positive demand innovation (i.e. $a$ increases), OPEC will only do it if $\alpha$ is not constant. Total supply on the market is given by:

$$
Q_{T}=\frac{a-\alpha c}{b}
$$

Substituting equations 5, 3 and 4 in 1, it is immediate to show that, without structural changes, the discounted value of OPEC future profits can be expressed as:

$$
\Pi=\frac{1}{1-\beta} \frac{(\alpha-1)^{2} c^{2}}{b}
$$

\footnotetext{
${ }^{4}$ Notice that $Q_{N O}$ is constrained by the capacity of the fringe firms, and therefore $Q_{N O} \leq K$, where K stands for the fringe firms capacity.
} 
As $\mathrm{T}$ is finite, the game repeats over time unchanged but exogenous factors may intervene to alter market conditions, for instance an improvement in the production efficiency of non-OPEC producers. Technology progress can decrease $\alpha$ and the dominant player will revise its production accordingly. OPEC's profits will be negatively affected via two channels: 1) the profit margin is compressed and 2) the residual demand is reduced. However, does this provide an incentive to OPEC to revise its production strategy?

\subsection{When are strategic deviations from the equilibrium preferable?}

So far, we have defined the equilibrium of the oil market under a dominant firm-competitive fringe model based on the assumption that OPEC will set a price higher than the marginal cost of the fringe firms, so all the firms can compete in this market. However, is it always optimal for OPEC to act like a monopolist on the residual demand? Or would it be better to act strategically? In this subsection, we analyze two new strategies that OPEC can follow and determine under which conditions OPEC has incentives to deviate from the "equilibrium" of acting as a monopolist on the residual demand.

In the spirit of Behar and Ritz (2017), we imagine two possible strategies that can be enforced by the dominant player: in the former OPEC can decide to regain market share by pushing some fringe firms out of the market, in the latter OPEC decides to target the oil market price to stabilize it around a desired value. ${ }^{5}$

We therefore assume these two strategies to be possible objectives of OPEC and investigate under which conditions OPEC has incentives to deviate from the equilibrium. As $\mathrm{T}$ is finite, the game repeats over time unchanged but following any change in market conditions, OPEC will reconsider its strategy and evaluate whether deviating from the equilibrium is preferable.

Specifically, defining $\Pi_{P T}$ the profits obtained under Price Targeting and $\Pi_{o}$ the status quo profits, OPEC will follow a Price Targeting Strategy when $\Pi_{P T}>\Pi_{o}$. In this case OPEC will cut production by a $\Delta Q_{O}$ to support oil prices, given new market conditions. This means that as non-OPEC production expands for exogenous reasons, OPEC will reply by cutting production, and hence the two productions will move in an opposite direction under a Price Targeting Strategy in the same period . This strategy is preferable when ${ }^{6}$ :

$$
\begin{aligned}
& p_{P T}-p_{0}= \Delta p_{P T}>\left(p_{0}-c\right) \frac{\Delta Q_{O}}{Q_{O}-\Delta Q_{O}} \\
& \Delta p_{P T}>(\alpha-1) c \frac{\Delta Q_{O}}{Q_{O}-\Delta Q_{O}}
\end{aligned}
$$

\footnotetext{
${ }^{5}$ This can be driven by idiosyncratic reasons, such as maintaining their internal fiscal balance, which are not explicitly modeled in our framework.

${ }^{6}$ See Appendix 6.1.1 for derivation details.
} 
where $p_{0}$ and $Q_{O}$ are the equilibrium values of price and OPEC production when OPEC acts as a monopolist on the residual demand. Similarly, a deviation from the status quo, consisting in increasing production above the equilibrium level by $\Delta Q_{O}$, is preferred by OPEC in order to regain market shares when $\Pi_{M S T}>\Pi_{o}$. Differently from the previous strategy, in this situation both oil productions for OPEC and non-OPEC move in the same direction at the same time; a condition verified when:

$$
\begin{aligned}
p_{M S T}-p_{0}= & \Delta p_{M S T}>\left(p_{0}-c\right) \frac{\Delta Q_{O}}{Q_{O}+\Delta Q_{O}} \\
& \Delta p_{M S T}>(\alpha-1) c \frac{\Delta Q_{O}}{Q_{O}+\Delta Q_{O}}
\end{aligned}
$$

Both conditions state that profits gains from deviation must be larger than profits losses. The conditions under which equation 8 and 9 are satisfied depend fundamentally on the assumptions made about demand schedule and the functional form of non-OPEC production costs.

Focusing on the functional form of non-OPEC production costs, when $\alpha$ is constant, Market Share Targeting is always the preferred strategy. This is intuitive because if the marginal production cost of non-OPEC does not vary with $Q_{N O}$, every effort made by OPEC to raise the price will only result in non-OPEC expanding its share as the equilibrium price remains determined by non-OPEC production costs. Under such conditions, Price Targeting is clearly sub-optimal but Market Share Targeting is instead preferred to the situation of OPEC playing monopolistic on the residual demand. By the same token if OPEC increases, even marginally, its production, the price will decrease below $\alpha c$, resulting in non-OPEC producers leaving the market and OPEC earning the monopoly profits shaved by a tiny value; therefore Market Share Targeting results the winning strategy. Less trivial is the situation when $\alpha$ increases with total non-OPEC production. ${ }^{7}$

In the case of a linear demand schedule, imposing equation 2 , it is immediate to obtain that OPEC will adopt a Price Targeting Strategy when:

$$
\frac{\Delta Q_{N O}^{P T}}{\Delta Q_{O}^{P T}}<1-\frac{\left(\alpha_{0}-1\right) c}{b} \frac{1}{Q_{O}-\Delta Q_{O}^{P T}}
$$

and it will pursue a Market Share Targeting strategy provided:

$$
\frac{\Delta Q_{N O}^{M S T}}{\Delta Q_{O}^{M S T}}>1+\frac{\left(\alpha_{0}-1\right) c}{b} \frac{1}{Q_{O}+\Delta Q_{O}^{M S T}}
$$

\footnotetext{
${ }^{7}$ The case of unit costs decreasing in total production, that is increasing return to scale is not considered as it will always lead, in the absence of maximum production capacity, to the entire market concentrated in the hands of a single producer.
} 
Ultimately whether one of the two strategies is preferred to the status quo and which of the two strategies is pursued depends on the reaction of non-OPEC production to OPEC moves, determined by the functional form of the fringe firms costs. ${ }^{8}$

When non-OPEC production costs are increasing in $Q_{N O}$, if OPEC attempts to raise the price above the equilibrium by cutting its production (Price Targeting strategy), the possibility of nonOPEC expanding its own production by the same amount will be limited by the increase in marginal production costs. It must therefore exist a range of $\alpha$ for which Price Targeting is feasible and optimal.

Similarly in order to regain market shares, OPEC will expand production pushing down the oil market price, non-OPEC then cuts back on its production but less than OPEC's initial expansion, as unit production costs decrease. In conclusion, when $\alpha$ increases with total non-OPEC production, it is not obvious any longer that Market Share Targeting is preferred to the status quo and to Price Targeting.

Although it is not necessary for the sign restrictions imposed in the empirical model, we can determine the range of parameters under which it is optimal for OPEC to deviate from the equilibrium. In particular, it can be proved that under the linear demand schedule hypothesis, assuming that nonOPEC production costs also increase with production linearly $\left(\alpha=\delta Q_{N O}\right)$, we have that:

$$
\frac{\Delta Q_{N O}}{\Delta Q_{O}}=-\frac{b}{\delta c+b}
$$

The ratio of non-OPEC to OPEC production decreases with demand sensitivity to prices $\left(\frac{1}{b}\right)$ and relative to inefficiency of non-OPEC. More importantly, exogenous shocks to $\delta$ can induce OPEC to start or cease a strategy. Finally, replacing equation 10 in 8, we obtain the optimal OPEC deviation from status quo under Price Targeting: ${ }^{9}$

$$
\frac{\Delta Q_{O}}{Q_{O}}<\frac{-b}{\delta c}
$$

and the optimal OPEC deviation from the status quo under Market Share Targeting is found by replacing 10 into $9:^{10}$

$$
\frac{\Delta Q_{O}}{Q_{O}}>\frac{b}{\delta c}
$$

Therefore for $\frac{-b}{\delta c}<\frac{\Delta Q_{O}}{Q_{O}}<\frac{b}{\delta c}$, the status quo (acting as a monopolist on the residual demand) is preferred by OPEC. Small perturbations in quantities will not be sufficient to deviate from the optimal equilibrium, but relevant changes in production can trigger a switch in the optimal strategy.

\footnotetext{
${ }^{8}$ It is immediate to verify that as long as OPEC production is positive, it never happens that both conditions 2.1 and 2.1 are satisfied at the same time.

${ }^{9}$ See appendix 6.1 for derivation details.

${ }^{10}$ see appendix 6.1 for derivation details.
} 
Moreover whatever strategy is followed, it has to become more aggressive as $\delta$ decreases, which is when non-OPEC producers become relatively more efficient, or when oil prices are more sensitive to a change in quantities.

Last, like in other theoretical frameworks, following positive demand shocks total supply increases. In particular, maintaining the assumption of increasing non-OPEC marginal production costs, demand shocks originate shifts in the same direction of both OPEC and non-OPEC productions, regardless of whether the pursued strategy is the status quo, Price or Market Share targeting. Moreover, demand shocks consisting in $\Delta a$ do not generate switches of OPEC strategy since they do not enter the two conditions 12 and 11.

\subsection{Price Targeting vs Market Share targeting}

We have identified a range of parameters under which deviating from the status quo of playing monopolistic on the residual demand curve seems to be optimal. However, it is also relevant to know when OPEC prefers to follow a Market Share Strategy or a Price-Targeting Strategy.

OPEC decides its optimal strategy based on its inter-temporal profit maximization problem given the information set available at each time t. OPEC will follow a Price Targeting Strategy whenever:

$$
\begin{aligned}
\Pi_{P T} & >\Pi_{M S T} \\
\left(p_{0}+\frac{\delta b c \Delta Q_{O}}{b+\delta c}-c\right)\left[Q_{O}-\Delta Q_{O}\right] & >\left(p_{0}-\frac{\delta b c \Delta Q_{O}}{b+\delta c}-c\right)\left[Q_{O}+\Delta Q_{O}\right] \\
Q_{O} & >\left(p_{0}-c\right) \frac{b+\delta c}{\delta b c} \\
\frac{Q_{O}}{Q_{N O}} & >\left(\delta-\frac{a+c}{b+\delta b c}\right) \frac{b+\delta c}{\delta b c}
\end{aligned}
$$

Price Targeting is preferred to Market Share Targeting as long as OPEC production remains above a precise threshold $(\delta)$, and therefore a certain market share seems to be guaranteed by OPEC. However, whenever OPEC's production is largely and negatively affected, for instance by a fierce competition from the fringe firms, OPEC might find optimal to switch from one strategy to another in order to defend its production, even at the cost of accepting a drop in oil prices.

This simple framework provides a better understanding of strategic interactions in the oil market in order to assess the impact of OPEC's strategies on oil price dynamics. It also provides underpinnings to bridge theoretical considerations with the empirical identification of the oil market. It highlights the three possible strategies that OPEC can pursue and provides precise conditions under which one strategy prevails on the other: 1) act as a monopolist on the residual demand, 2) target oil prices 
to keep them around a desired target, by cutting down its own production in some cases, 3) regain market shares if competitors are expanding.

More importantly, this simple theoretical model shows that following an exogenous shock to nonOPEC production, OPEC can decide to switch from one to another strategy. When OPEC finds optimal to pursue a Price Targeting Strategy, it will cut on its original production following a nonOPEC positive supply shock, therefore the two productions changes will have opposite signs. When Market Share Targeting is found to be optimal, OPEC will increase beyond its initial status quo level its production. Notice that the framework encompasses the possibility of uncertainty around which strategy is optimal to play as non-OPEC efficiency can change exogenously. It also exists a range of market conditions (demand and competitor efficiency) that accommodates a period of inertia during which no active strategy is pursued. This can explain OPEC's behaviour during the initial stages of the shale revolution.

Based on the policy reaction function of OPEC to non-OPEC supply shocks depending on the strategy pursued, in section 3 we present an empirical model that aims at formalizing the theoretical considerations presented in this section. Our ultimate goal is to better understand oil price dynamics in recent decades, and specifically to assess in which episodes OPEC was acting strategically.

\section{Empirical strategy}

\subsection{Data}

We jointly model a vector of five time series $Y_{t}=\left[Q_{O p e c}, Q_{N o n-O p e c}, R E A, P_{o i l}, I n v\right]$, where $Q_{O p e c}$ and $Q_{N o n-O p e c}$ are, respectively, oil production from OPEC and Non-OPEC, $R E A$ is a measure of global real economic activity, $P_{o i l}$ is the real price of oil, and $I n v$ are oil inventories. All time series are transformed to achieve stationarity.

OPEC and non-OPEC production are obtained from the Monthly Energy Review published by the US Energy Information Administration (EIA), and they are expressed in monthly percentage changes. In order to measure global economic activity we use a monthly series of world GDP obtained by interpolating quarterly world GDP growth. ${ }^{11}$ The measure of real oil prices is derived from the average Brent crude prices, obtained from the International Financial Statistics (IFS), and deflated by the US consumer price index. Brent prices enter the model in log-levels. Finally, owing to the lack of available data and following Kilian and Murphy (2014), world crude inventories are proxied by

\footnotetext{
${ }^{11}$ Results do not change fundamentally when using Kilian's measure for global economic activity, which is based on dry cargo single voyage ocean freight rates, see Kilian (2009). Notice, however, that the performance of this indicator, as pointed out by ?, has deteriorated in recent years. During the slowdown in economic activity in early 2016, for instance, the negative spike in Kilian's indicator would have predicted a more severe crisis than the Global Financial Crisis, casting doubts about its suitability as a leading indicator.
} 
monthly changes in total US crude oil inventories, rescaled by the ratio of OECD to US petroleum stocks, which are taken from the EIA. ${ }^{12}$

\subsection{A SVAR model}

We model the vector of variables $Y_{t}$ in a Structural Vector Auto Regression (SVAR). We follow the previous literature including 24 lags (Kilian and Murphy, 2014) and employ monthly data. The structural form representation of the model is as follows:

$$
A_{0} Y_{t}=B(L) Y_{t-1}+\epsilon_{t}
$$

$Y_{t}$ is a vector of five endogenous variables, including (1) the monthly percentage change in OPEC crude oil production, (2) the monthly percentage change in non-OPEC crude oil production, (3) the monthly growth rate of the interpolated global GDP, (4) the log-real price of oil, (5) the monthly changes in global oil inventories. The matrix $A_{0}$ shapes the contemporaneous interaction among the endogenous variables, while $\mathrm{B}(\mathrm{L})$ is a matrix polynomial and $\epsilon_{t}$ is a vector of structural disturbances. ${ }^{13}$ The reduced form representation of the model is the following:

$$
Y_{t}=C(L) Y_{t-1}+u_{t}
$$

where $u_{t}=A_{0}^{-1} B(L)$ and $C(L)=A_{0}^{-1} B(L)$. The reduced form residuals have a full rank covariance matrix, $\Sigma=A_{0}^{-1} A_{0}^{-1 \prime}=D D^{\prime}$. Identification of the structural shocks is achieved via sign restrictions on the columns of $D$ following the standard method popularized by Arias, Rubio-Ramirez, and Waggoner (2018).

In order to identify structural shocks and to study their effects on the price of oil we need to place restrictions on the structural impact matrix $D$. A number of papers have shown that fluctuations of the price of oil in the global oil market can be mostly attributed to three fundamental shocks, namely oil supply, oil demand and precautionary demand shocks, see for instance Kilian and Murphy (2014) and Baumeister and Hamilton (2015). We deviate from these analyses by allowing for a richer characterization of the behaviour of oil suppliers, given the focus of our analysis on the strategic interaction of oil producers. The existent empirical literature has typically bundled together the behaviour of OPEC and non-OPEC producers and considered a single aggregate global supply shock. To see how

\footnotetext{
${ }^{12}$ As OECD petroleum series is only available from 1987, the series is backcasted from 1973 using the growth rate of US petroleum inventories, closely correlated to overall OECD changes especially in the early years of the sample (see Kilian and Murphy (2014)).

${ }^{13}$ An intercept and seasonal dummies are also included in the model.
} 
such an aggregate shock is identified in a SVAR model of the type hereby employed, let us suppose that such oil supply shock is identified as the first shock in the system. This would be obtained by imposing restrictions on the signs of the first column of $\mathrm{D}$, let us call it $d_{1}$. In particular, an exogenous tightening of oil supply would lead to a fall in oil production, an increase in prices and a contraction of global economic activity. Therefore, the first three elements of $d_{1}$, corresponding to the response of (1) OPEC production, (2) non-OPEC production and (3) real economic activity are supposed to be negative, while the fourth one, corresponding to the response of the real price of oil, is supposed to be positive. However, the theoretical model derived in section 2 suggests that OPEC and non-OPEC producers interact strategically. Such strategic interaction, in turn, implies that OPEC producers would likely adjust their response to non-OPEC producers in a time-varying fashion, depending both on market conditions and on domestic economic considerations. ${ }^{14}$

One would be tempted to address this issue by making the coefficients in $d_{1}$ time-varying, but this by itself would not solve the problem. What one needs, in fact, is to allow for the second element of $d_{1}$ (corresponding to the behaviour of OPEC suppliers) to switch sign over time so as to give OPEC the possibility to follow non-OPEC production (so as to target market shares) or to partially/completely offset it (so as to target prices). In order to strike a sensible balance between flexibility and simplicity, our solution consists of identifying an additional structural shock, which imposes opposite signs on the response of OPEC and non-OPEC production. In other words, we identify two independent structural shocks - a "Market Share Targeting" shock and a "Price Targeting" supply shock, related to the strategic interactions of OPEC and non-OPEC supply decisions. The former is the typical global oil supply shock identified as in Kilian and Murphy (2014) and Baumeister and Hamilton (2015), where OPEC and non-OPEC production moves in the same direction. The latter is identified by allowing OPEC to move its production in the opposite direction to that of non-OPEC, in order to partially stabilize prices. Besides these shocks, we also identify a global demand and a precautionary demand for oil shock, as in Kilian and Murphy (2014). Table 1 reports a summary of the sign restrictions imposed on the first four columns of $D$ in order to recover the structural shocks.

The key identifying assumptions are sign restrictions imposed on the responses at time 0 of the five variables to the structural shocks, as well as dynamic restrictions on some of the variables. The novelty of this set-up is that it exploits specific conditions derived within a simple theoretical framework to identify the two types of supply shocks. If OPEC seeks to maintain its market share (MST strategy), it reacts to expansions (declines) in non-OPEC production by also increasing (decreasing) its supply. In this case, both productions move in the same direction at the same time, and therefore the contemporaneous responses have the same sign, leading to an amplification of the decrease (increase)

\footnotetext{
${ }^{14}$ For instance, domestic fiscal balance considerations could shape the decision by OPEC members to react one way or another to a supply shock originating in non-OPEC countries.
} 
Table 1: Identification Restrictions

\begin{tabular}{lcccc}
\hline Variables & $\begin{array}{c}\text { Market share } \\
\text { targeting supply }\end{array}$ & $\begin{array}{c}\text { Price } \\
\text { targeting supply }\end{array}$ & $\begin{array}{c}\text { Aggregate } \\
\text { demand }\end{array}$ & $\begin{array}{c}\text { Speculative } \\
\text { demand }\end{array}$ \\
\hline OPEC production & - & - & + & + \\
Non-OPEC production & - & + & + & + \\
Real activity & - & & + & - \\
Real price of oil & + & & + & + \\
Inventories & & & + \\
\hline \hline
\end{tabular}

Notes: As commonly done in the literature, all responses have been normalized such as structural shocks have a positive impact on oil prices. Moreover, a fifth shock, not represented in the table, captures the linear combination of all unidentified shocks accounting for the unexplained part of variables' dynamics.

in oil prices. ${ }^{15}$ On the contrary the "Price Targeting supply shock", considers opposite movements in OPEC and non-OPEC production. If OPEC aims at stabilizing oil prices around a target (for given global demand conditions), it must drain the eventual excess supply by reducing its own supply to support prices. In this case, no sign restrictions are imposed on price and global activity since there are two forces operating in opposite directions and the overall effect on prices and activity is ambiguous, depending on the net impact on production (see Table 1). Notice that, at any point in time, the model will assign some of the changes in the price of oil to both the Market share and to the Price targeting strategies. This simply implies that following an exogenous increase in production from non-OPEC producers, the overall net reaction of OPEC producers will be determined by the sum of the two shocks. Despite being a crude shortcut for allowing OPEC to react differently at each point in time, this identification strategy allows us to capture the main qualitative implications of the theoretical model. Furthermore it allows for an endogenous optimal selection of the strategy pursued within a single econometric workhorse. This compares with other works (see Golombek, Irarrazabal, and Ma (2018)) where the dominant OPEC and the competitive OPEC paradigms lead to alternative estimation methodologies (a non linear instrumental variable and a 3 stage least square method respectively) and econometric models carried out on different time frames.

Similarly to previous works, positive aggregate demand shocks in the oil market (i.e. a shift in the demand curve) are identified by simultaneous increases in oil prices and production in both OPEC and non-OPEC countries. A positive speculative demand shock gives origin to a situation when market players purchase oil inventories ahead of expected future shortages in the oil market and as a result the current level of inventories and the real price of oil rise. At the same time, higher oil price boosts oil production in OPEC and non-OPEC countries while aggregate economic activity decreases. ${ }^{16}$

\footnotetext{
${ }^{15}$ To select only supply shocks with some persistent effect, we further impose that the oil price reaction persists for at least 12 months.

${ }^{16}$ Notice that we do not impose any particular elasticities bounds on oil supply and demand. The main reason is that there is no consensus on what the correct values of elasticities that should be imposed are. A recent paper by Caldara, Cavallo, and Iacoviello (2019), for instance, finds that the short-run oil supply elasticity might be as high as 0.077 , three times higher than the supply bound (0.0258) imposed in Kilian and Murphy (2012).
} 


\section{Results}

We name 3-shocks and 4-shocks models, respectively, a standard model which identifies, demand, supply and precautionary demand shocks and our model which distinguishes two types of supply shocks in addition to demand and precautionary demand shocks. In order to highlight the main contribution of the novel framework accommodating for producers strategic interactions, we rely first on the comparison of the forecast error variance decomposition of oil prices between the 3 -s and the 4-s model. ${ }^{17}$ We then move to compute oil supply and oil demand elasticities, and finally comment on the historical decomposition.

\subsection{Forecast Error Variance Decomposition}

We start by comparing how the 3-s and the 4-s models decompose the oil prices' forecast error variance, see Figure 2. The plot is organized in four panels. The top-left panel reports the share of forecast error variance that is explained by the typical supply shock in the 3 -s model and by the Market

Figure 2: Forecast Error Variance Decomposition of oil prices: comparing the 3-s and 4-s models
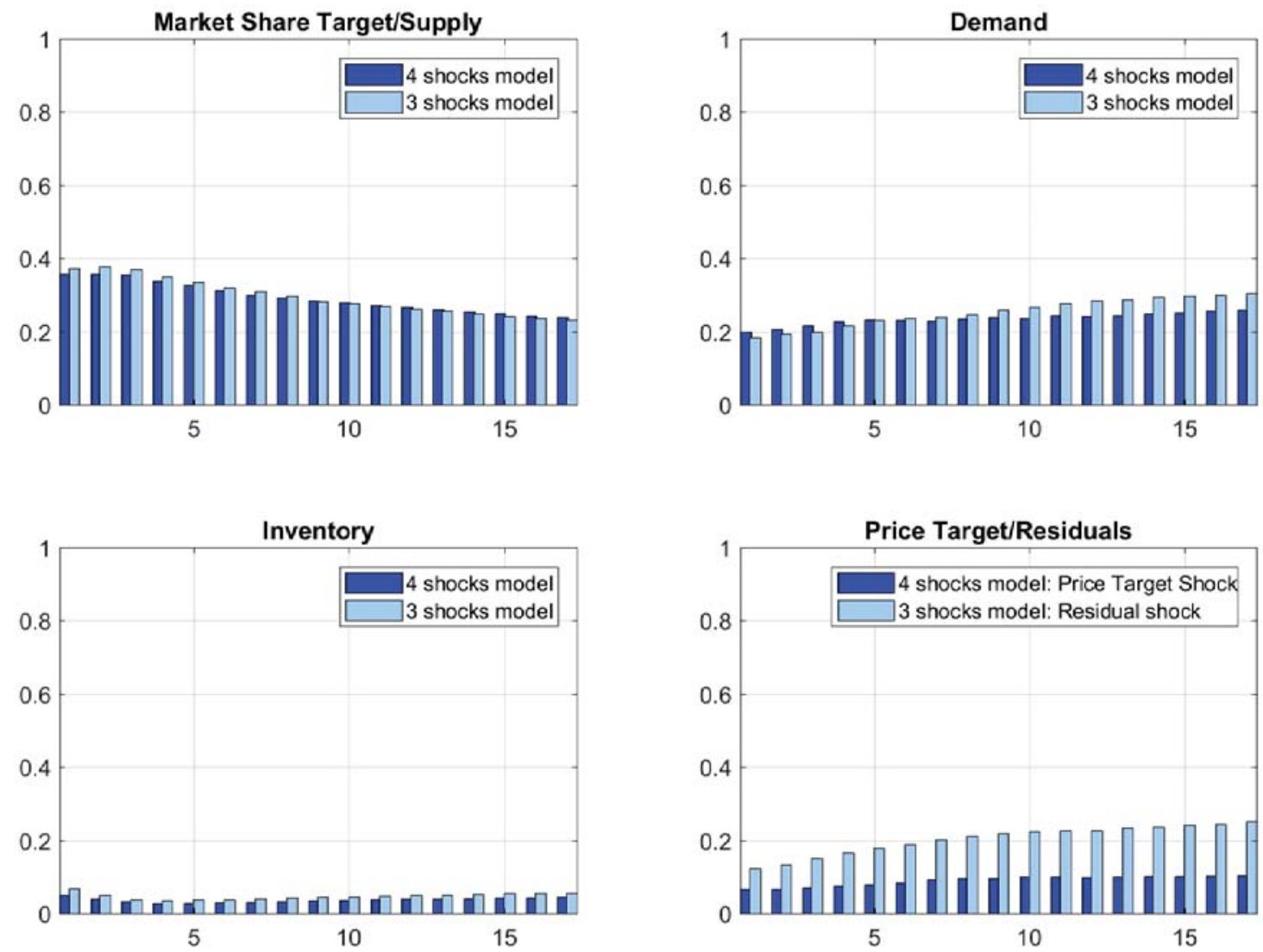

Notes: The 4-shock model refers to the new model that distinguishes between two types of supply shocks, while the 3-shock model focuses on a standard model which identifies, demand, supply and precautionary demand shocks.

\footnotetext{
${ }^{17}$ Impulse response functions are shown to be well behaved in the appendix.
} 
Share targeting shock in the 4-s model. The top-right and bottom-left panels report the shares of, respectively, the demand and the speculative demand shocks for both models. Finally, the bottomright panel compares the share of variance that in the 3-s model is attributed to the residual shock, to the share that in our setup is captured by the Price Targeting shock.

We draw attention to three results. First, the supply shock in the 3-s model and the Market Share Targeting shock in the 4-s model explain by large the same share of oil price fluctuations (around 40 percent at short horizons and about half as much at longer horizons). This, by itself, suggests that our newly identified shock is not subtracting explanatory power from the traditional supply shock. Second, in our model global demand is slightly less relevant than in the 3-s model, especially at longer horizons, while the relevance of shocks that originate from precautionary demand for inventories is somewhat lower. Last and most importantly, the Price Targeting shock explains almost an additional 10\% of the FEVD, which in the 3-s is left non-identified and therefore attributed to the residual shock. Indeed the part of the variance of the forecast errors explained by the residual. ${ }^{18}$ is substantially reduced in the 4-shocks framework (to about half of what is in the 3-s model), suggesting that the added model flexibility captures indeed some relevant heterogeneity in the behaviour of OPEC supply over the considered sample.

\subsection{Elasticities}

Based on the structural shocks identified in our specification, we can estimate implied short-run price elasticities for oil demand and oil supply. Furthermore, having split oil production in OPEC and non-OPEC countries, we allow for heterogeneous oil supply elasticities in these two economic areas, by looking at how their production react in the face of a structural demand shock. ${ }^{19}$

Table 2 summarizes the median short-run price elasticities derived in our model. They turn out to be consistent with those recently estimated of the recent literature. Indeed, the median of the aggregate oil supply elasticity is 0.10 , qualitatively close to the elasticity obtained in Caldara, Cavallo, and Iacoviello (2019) and in Baumeister and Hamilton (2019). More specifically, Baumeister and Hamilton (2019) derive a short-run oil supply elasticity of 0.15 using Bayesian inference with relaxed prior information on the size of elasticities, while Caldara, Cavallo, and Iacoviello (2019) estimate a 0.077 short-run supply elasticity using country-level instrumental variable regressions.

\footnotetext{
${ }^{18}$ Not shown in the graph.

${ }^{19}$ Given that we model two different producers that can adopt different strategies we need to make some assumptions when estimating elasticities. The global oil price supply elasticity is obtained by considering the overall percentage increase in global oil production determined by OPEC and non-OPEC (conditional on a demand shock) and dividing the resulting percentage change by the percentage increase in global oil prices. The price elasticity of demand is obtained conditioning on the Market Share targeting shock.
} 
Turning to the difference between OPEC and non-OPEC supply elasticity, unsurprisingly we find that the elasticity of OPEC supply is higher than that of non-OPEC supply. A similar result, albeit with very different techniques, is obtained by Caldara, Cavallo, and Iacoviello (2019), who estimated an elasticity of 0.22 for Saudi Arabia, 0.19 for the rest of OPEC members and non significantly different from zero for non-OPEC countries. While our results are qualitatively similar for OPEC countries with a supply elasticity of 0.2 , we also derive a small positive supply elasticity for nonOPEC countries, of around 0.06. OPEC adjust production in response to price changes more easily due to available spare capacity, but also to optimally decided production policies.

Table 2: Median price elasticities of crude oil supply and demand

\begin{tabular}{lcccc}
\hline Elasticities & Our model & KM14 & CCI19 & BH19 \\
\hline $\begin{array}{l}\text { Price elasticity of crude oil demand } \\
\text { Price elasticity of crude oil supply }\end{array}$ & -0.28 & -0.08 & -0.07 & -0.35 \\
- Global & 0.10 & 0.03 & 0.08 & 0.15 \\
- OPEC & 0.20 & & 0.19 & \\
- non-OPEC & 0.06 & & -0.01 & \\
\hline \hline
\end{tabular}

Notes: Estimates Km14 refers to Kilian and Murphy (2014), CCI19 refers to Caldara, Cavallo, and Iacoviello (2019) and BH19 refers to Baumeister and Hamilton (2019). Notice that in the case of KM14, elasticities refer to the upper bound for supply and to lower bound for demand.

The short-run demand elasticity $(-0.28)$ is also closer to the estimates retrieved in the recent literature. Indeed, there is an extensive literature on oil demand elasticities, with heterogeneous results as elasticities range from -0.81 for the long-run price elasticity of gasoline demand (Hausman and Newey (1995) to -0.07 of short-run oil elasticity of Caldara, Cavallo, and Iacoviello (2019). ${ }^{20}$ However, the recent literature challenges previous estimates and points to lower elasticities. Caldara, Cavallo, and Iacoviello (2019) find a demand elasticity around -0.07 using data from 1985 to 2007. Gelman, Gorodnichenko, Kariv, Koustas, Shapiro, Silverman, and Tadelis (2016) retrieve a short-run elasticity for gasoline of -0.22 . Therefore, a short-run elasticity around -0.285 is reasonable for an average estimation using a larger sample period, from 1973 to 2017, as there is a persistent decline in elasticities over time.

Since we model OPEC and non-OPEC supply separately, we also look at possible breaks over time in the oil supply elasticity of these two producers. In particular, we obtain a time-varying version of our VAR model using the non-parametric estimator by Giraitis, Kapetanios, and Yates (2018) and identify at each point in time structural shocks. This allows us to have an estimate of time-varying supply and demand elasticities. The elasticity of OPEC and non-OPEC supply are obtained as price

\footnotetext{
${ }^{20}$ Of course, one needs to differentiate between crude oil and gasoline elasticities and between short and long run elasticities. While it is reasonable to argue that short-run elasticity is smaller than long-run elasticities, Hamilton (2009) makes the case that crude oil demand elasticity should be around half the gasoline demand elasticity since crude oil accounts for half the retail cost of gasoline.
} 
percentage changes following demand shocks, that is the response of production to oil price when an exogenous expansion or contraction of world demand occurs (e.g. shifts of the demand curve along the supply curve). Therefore, as explained in section 2, and irrespective of the strategy OPEC is pursuing, both OPEC and non-OPEC, to a different degree, will adjust their supply in the same direction to accommodate demand at least partially. ${ }^{21}$ The evolution of supply elasticities is shown in Figure 3 . As two different demand shocks have been identified in our model, the global aggregate demand shock and the speculative demand shock, we can derive different OPEC and non-OPEC supply elasticities conditional on each of these shocks. While the dynamics of supply elasticities are quite similar, oil supply seems to be slightly more elastic in the case of a speculative shock, pointing to a different reaction depending on the source of the shock.

Figure 3: Time varying supply elasticity
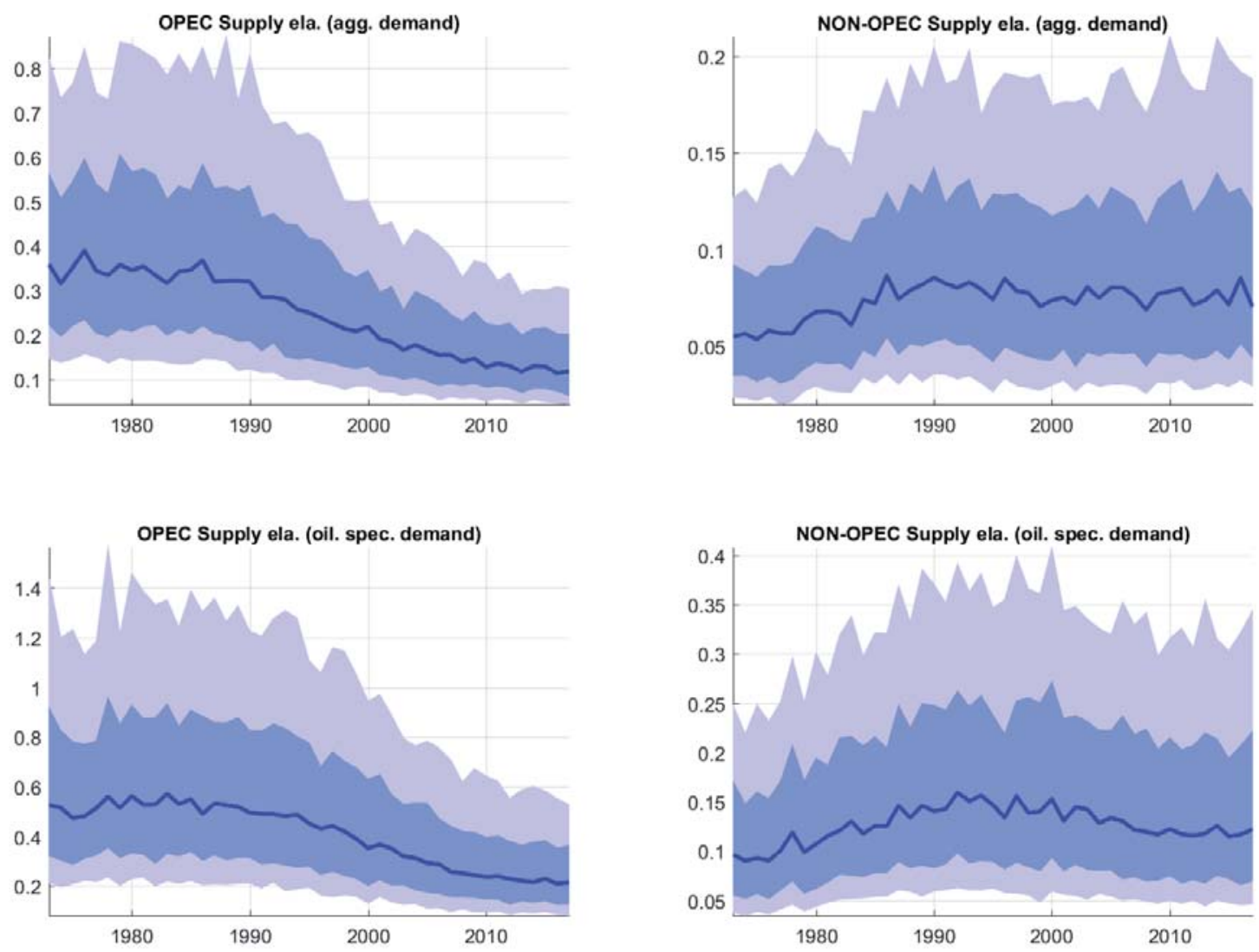

In addition, these time-varying supply elasticities confirm that OPEC elasticities are higher than non-OPEC elasticities for both demand shocks. Nevertheless, while OPEC supply elasticity seems to decline, for non-OPEC countries it slightly increases over time. OPEC supply elasticities are relatively

\footnotetext{
${ }^{21}$ In section 2 we clarify that it is for a given demand level that, depending on the strategy pursued, OPEC may restrain its supply when non-OPEC expands its own, while the elasticity of OPEC and non-OPEC supply are computed over different demand schedules
} 
more elastic in the seventies and eighties with median elasticities between 0.3 and 0.4 when computed as shifts along the aggregate demand and around 0.5 when computed from shifts along the speculative demand, while currently they are around 0.15 and 0.2 , respectively. Focusing on non-OPEC timevarying supply elasticities, there is no evidence so far of a recent structural break in elasticities due to the surge in shale oil production in the US. Elasticities remained rather constant over the past two decades despite the fact that shale producers are able to stop and restart production more easily than conventional non-OPEC producers, see also Foroni and Stracca (2019). Two factors can be behind this result: the phenomenon is too recent for a structural break to be properly identified in a time series analysis which has to be performed including many lags (up to 24) and the share of shale oil in total production is still only around $6.5 \%$ of world oil and $11 \%$ of non-OPEC production.

Figure 4: Time varying overall demand elasticity

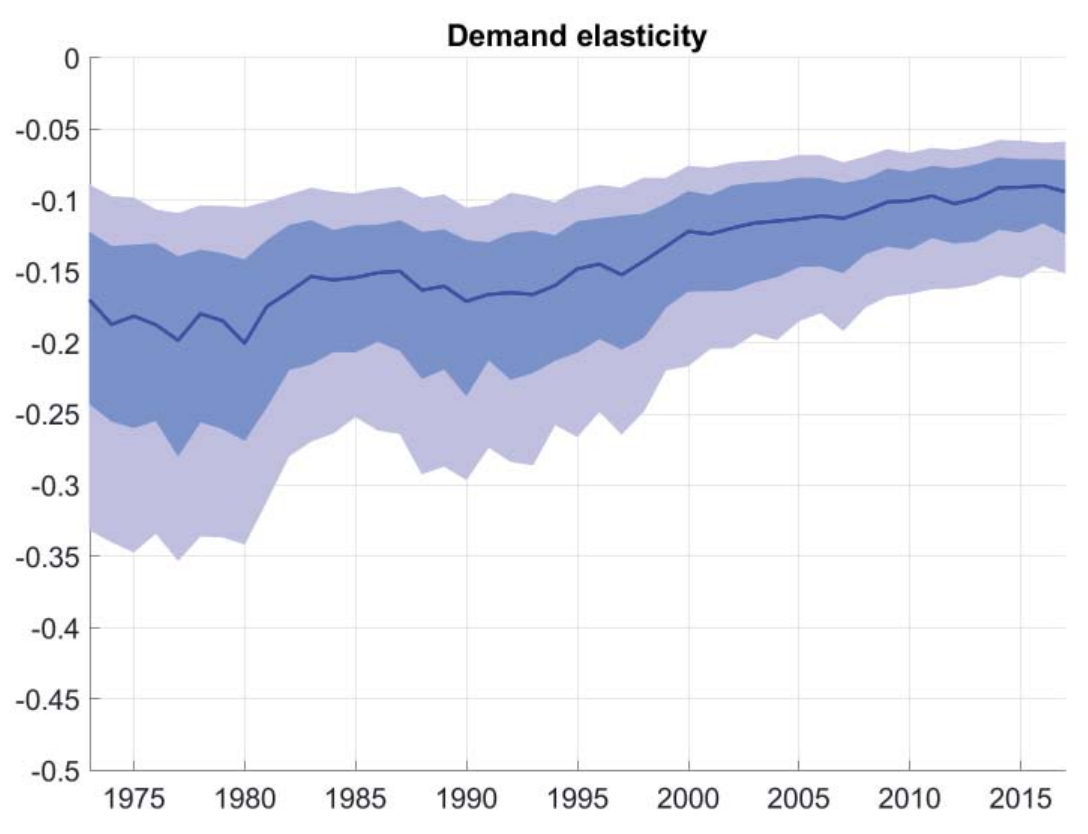

Estimates of oil demand time-varying elasticities, reported in Figure 4, indicate that this has declined quite markedly over time. In the seventies, oil demand median estimate was close to -0.2 until 1980, period in which they started their downward trend, in absolute value, until reaching a current level close to -0.1. The lower elasticity may result from economies having become more resilient to oil price shocks over time, chiefly owing to lower energy intensity. Its decline by a third since the early nineties is a consequence of the improved energy efficiency and the declining share of the energy intensive manufacture in global production. ${ }^{22}$

\footnotetext{
${ }^{22}$ A similar pattern is also shown in Baumeister and Peersman (2013). However, our estimates display a smaller volatility and their magnitudes are considerably smaller in the seventies and early eighties.
} 


\subsection{Historical Decomposition}

The historical decomposition of oil prices obtained from the 4-shocks model confirms some of the major findings of the previous literature but it also contains relevant innovations. To illustrate this point, in Figure 5 we show the contribution of each shock to fluctuations in the price of oil between 2000 and 2017 in the 3 -s and in the 4 -s models.

Supply shocks in the two models behave similarly. In Figure 5, top-left panel, the contribution of the Market Share Targeting shock of the 4-shocks model and that of the supply shock in the 3-s model overlap to a great extent over the entire period. It is worth remarking that the 4-shocks model imposes productions of OPEC and non-OPEC to comove, that is both must change at the same time in the same direction, for a Market Share Target shock to occur, while the 3-s only requires a positive innovation in the sum of the two. Therefore, despite the 4-s definition of Market Share Target is more restrictive, we find that its contribution to price dynamics is comparable to that of the supply shock identified in the 3 -s model.

Demand shocks continue to play a relevant role; in particular, they remain the most important factor explaining the pre-crisis spike. Nonetheless their contribution in our 4-s model is smaller both during the post-crisis fall as well as during the recovery phase of oil quotations in the aftermath of the global crisis, when also OPEC production strategy supported prices.

The importance of speculative demand shocks in explaining oil price evolution remains marginal (Kilian and Murphy (2014), Peersman, Baumeister, et al. (2009)). ${ }^{23}$

The Price Targeting strategy turns out to explain a relevant fraction of price variation in a few specific historical episodes. This can be seen in the bottom-right panel of Figure 5, which plots side by side the contribution of the unidentified shocks in the 3-s model (blue dashed line) and of the Price Targeting shock in our 4-s model (red solid line). It is clear that part of the unidentified shock the 3-s model is picked up in our richer set-up by the Price Targeting behaviour of OPEC countries. We take this as the validity of the 4-shocks model comes from the much smaller contribution to oil price dynamics of unidentified shocks. In particular, the Price Targeting strategy seems to have played a significant role in explaining oil price changes in the five years before the crisis, picking up part of the run-up in the price of oil that in the simpler 3-s model is attributed partly to demand, and partly left unexplained.

In a nutshell, this new model seems to provide a better understanding of key episodes with large changes in oil prices as explained in the following subsections.

\footnotetext{
${ }^{23}$ We noticed that this result seems to be rather sensitive to the indicator of global activity adopted. In particular, using the freight bulk dry rates used in Kilian (2009), seems to inflate the role of precautionary demand for inventories shocks
} 

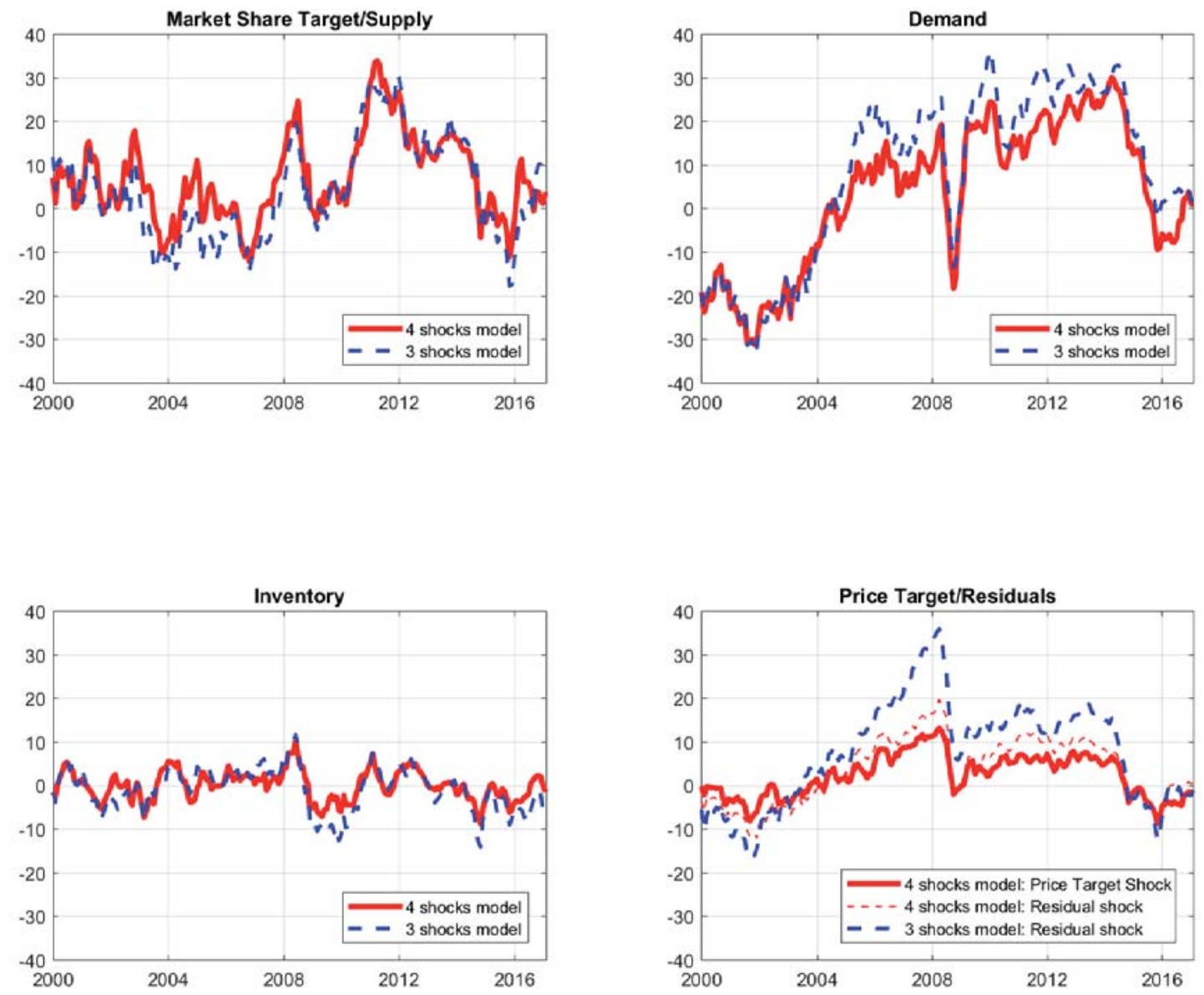

\subsubsection{The Great Price collapse and Saudi's ability to play as a swing producer}

Between 1981 and until 1985, OPEC, namely Saudi Arabia, tried to counteract the drop in the oil price by restricting its production. The period is generally regarded as one of limited demand growth, increasing non-OPEC production and declining prices. Hamilton names it the Great Price collapse and we follow here his labeling. Judging from declining prices, Saudis attempt has been considered ineffective by the previous literature, however our analysis helps reestablishing the role that supply played in this period. Figure 6 shows that supply shocks were offsetting, at least partially, the downward pushes due to weakening demand dynamics, hence revealing that Saudi Arabia strategy of curbing supply supported, indeed, oil quotations. Supply shocks between 1981 and early 1984 have constantly contributed positively to oil dynamics. Remarkably our analysis highlights with some precision the timing of Saudis decisions to give up the production restraint; in the chart the contribution 

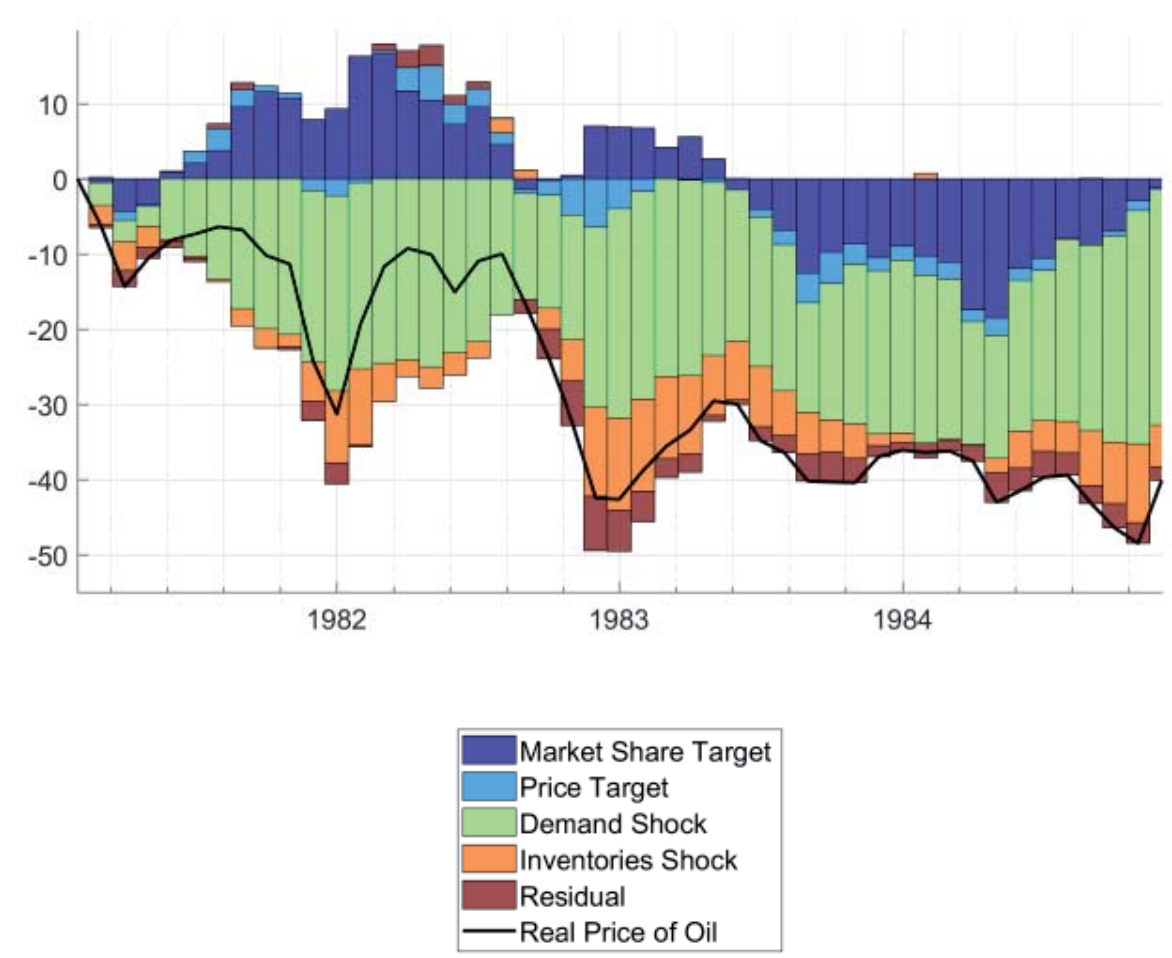

of supply shocks turns negative around the second quarter of 1984 shortly ahead of the Saudis public announcement.

\subsubsection{The emerging momentum}

The second episode we consider concerns the years around the global crisis from early 2003 to 2009 , what the literature named the commodities super-cycle. There is a large consensus suggesting that a buoyant growth from emerging economies, China above all, amid supply struggling to keep up the pace, drove prices to a new record in mid-2008, just before the global crisis (see for instance Hamilton (2011), Kilian (2009)). While the steadily rising oil demand from emerging economies was a key factor, we uncover also an active role of OPEC, which strove to keep the market tight and price elevated. The policy of Price Targeting was constantly sought over the entire period. Our empirical findings show this strategy enacted even during and right after the great oil price collapse (see Figure 7), an analysis indirectly confirmed by the particularly reduced level of oil inventories in this span of time. While Hamilton (2011) named it a period of Growing demand and Stagnant supply, we rather refer to this period as Growing demand and restrained supply since the strong demand was not fully accommodated by OPEC additional production which purposely did not want to bite into its spare 
capacity any further. Strikingly but not unexpected by practitioners, Figure 7 also shows the positive contribution of supply shocks to price dynamics while prices were free falling at the end of 2008

Figure 7: The emerging momentum

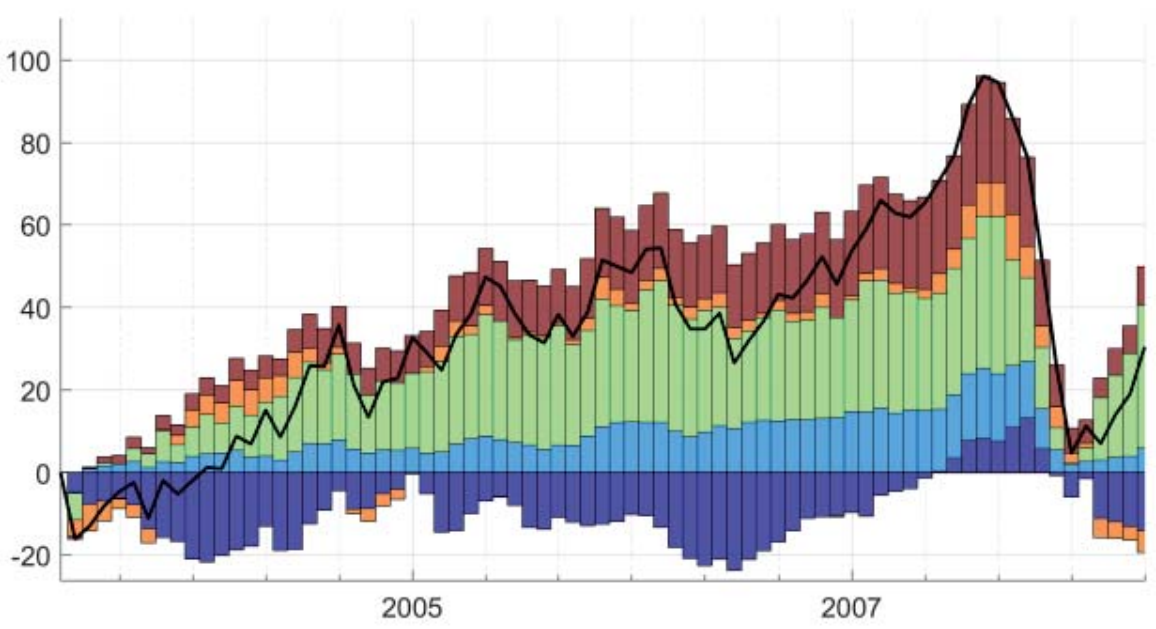

\begin{tabular}{|l}
\hline Market Share Target \\
Price Target \\
Demand Shock \\
$\square$ Inventories Shock \\
Residual \\
\hline Real Price of Oil
\end{tabular}

and early-2009. Indeed production statistics prove that OPEC withdrew within 6 months around 3 millions barrels a day over a semester and brought the market from a condition of excess supply into one of excess demand amid the global crisis.

\subsubsection{The age of shale}

More recently, during the shale age, demand factors were the major driver of oil prices until mid-2014. However the strategic interactions between OPEC and non-OPEC producers can explain a great deal of later developments. For instance, different strategies were pursued in the wake of the surge in shale oil production. In November 2014, OPEC announced that in order to regain market space, lost to shale producers, they were to abandon production targets. Our estimations suggest that starting from the second half of 2014, oil prices have been primarily driven by supply shocks (See Figure 8). Most of the drop experienced in the second half of 2014 was indeed due to supply factors, while demand factors started playing a role only later in 2015. 
Figure 8: Supply factors explain most of the price fall, demand dynamics were instead supporting prices in the second half of 2014

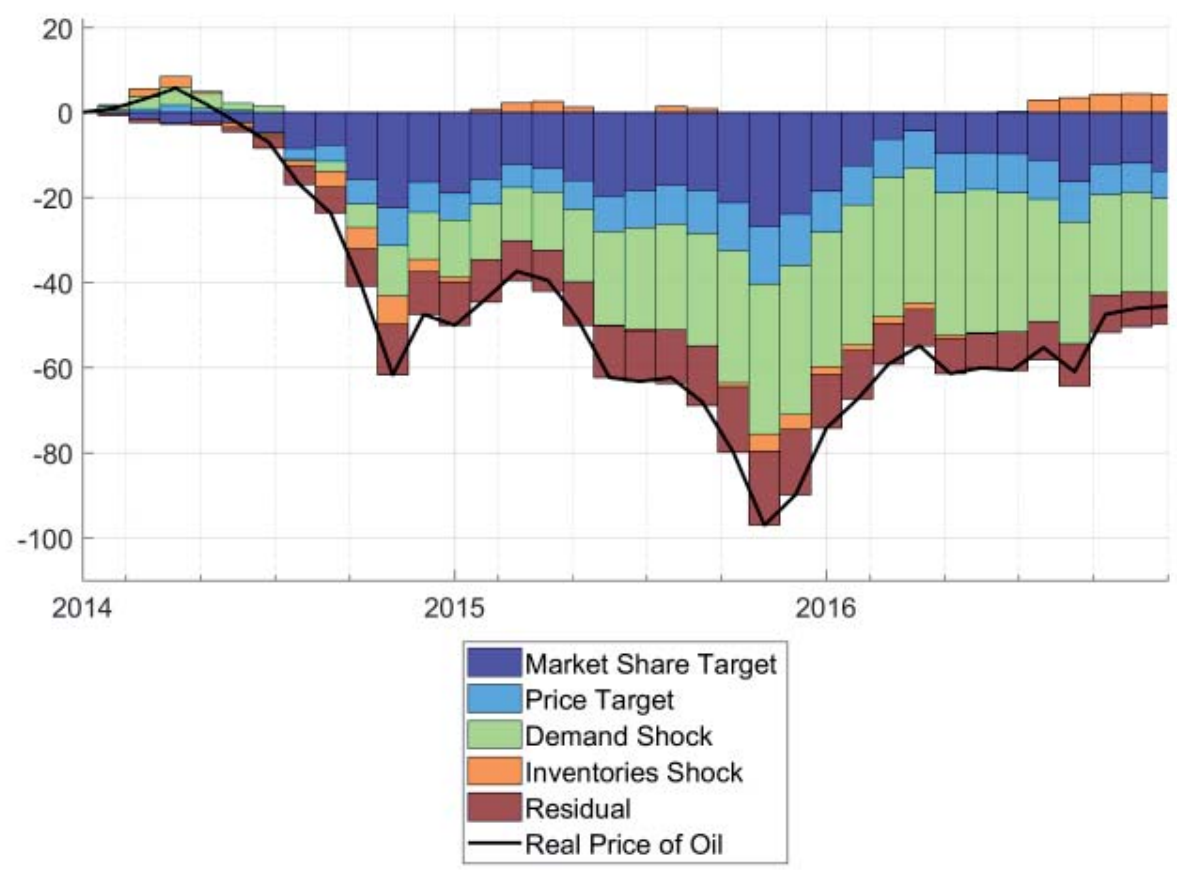

\subsubsection{The coordinated supply restraint}

However, as this strategy turned out to be more costly than expected in terms of fiscal revenues and shale oil producers were able to become more competitive in a low price environment, OPEC

Figure 9: The announcement triggered the recovery of oil prices ahead of the coordinated supply restraint

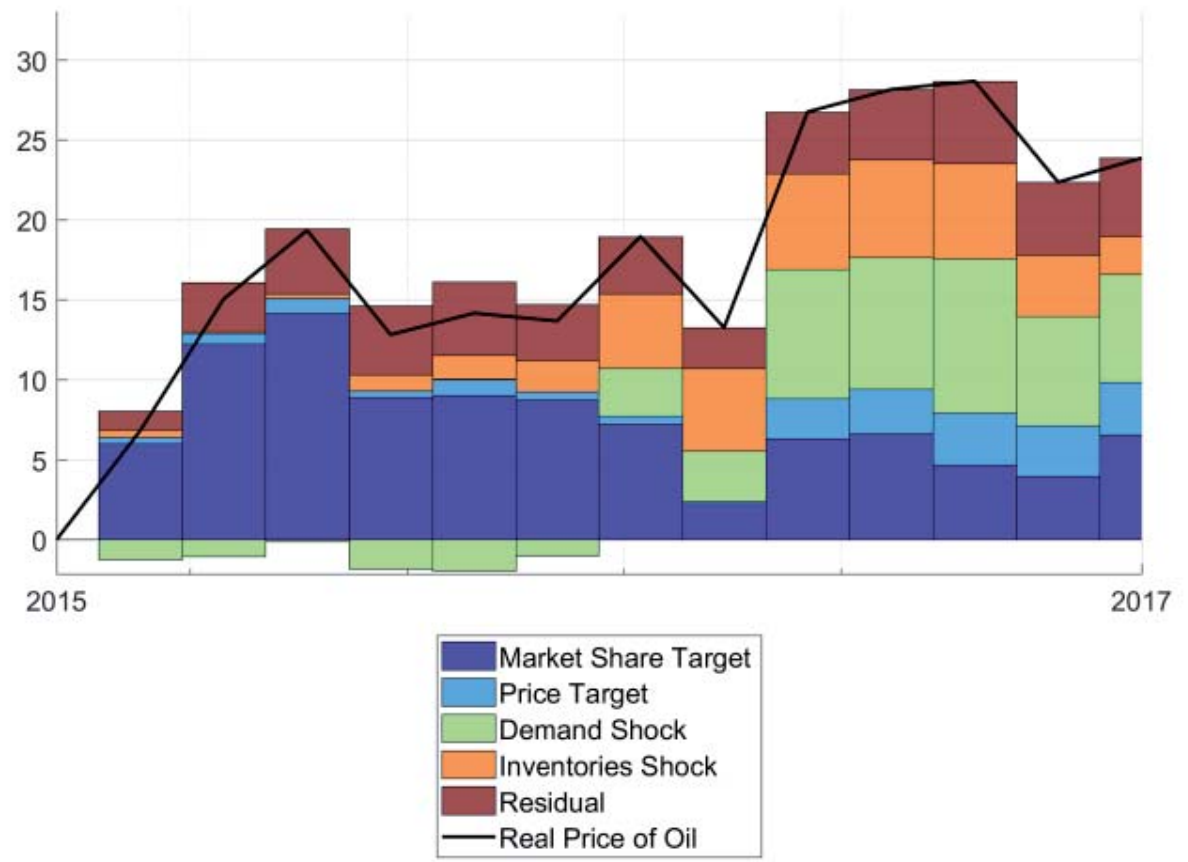


switched backed to a price stabilization strategy in order to re-balance the oil market. The price recovery, which started in mid-2016 and continued over 2017, was also triggered by this policy switch (See Figure 9). Our model results are consistent with the OPEC announcement (in November 2016), on the reinstatement of production quotas and a concerted production restraint. Both the supply policies Market Share Target and Price Targeting contributed to support the oil price recovery. Indeed, given US shale production had resumed growth, in order to have a pure Price Targeting policies, OPEC must have cut more the price for a pure Price Targeting to materialize. The relevance of Price Targeting over Market Share Target has grown over time.

\section{Conclusions}

In this paper we have explored the implications of strategic interplays among large oil producers for the determination of the price of oil in global oil markets. The model sheds light on how OPEC might decide either to follow non-OPEC production (in an attempt to defend market shares) or to counteract it in order to stabilize prices.

We then revisit the evidence on the structural drivers of oil prices in the light of a structural model where we separately identify Market Share Targeting from Price Targeting shocks. We find that OPEC's Price Targeting behaviour explains around 10 percent of the FEVD of the price of oil. Furthermore, although global demand shocks remain the major driver of oil price increases in the last commodity super-cycle (from 2004 onward), Price Targeting shocks contribute non negligibly to the rise in oil prices in the run-up to the crisis. Looking at specific episodes, the model highlights the contribution of OPEC's policy (namely Saudi Arabia) in preventing quotations from free falling during the great price collapse between 1981 and 1985, generally characterized by less buoyant demand, increasing non-OPEC supply and declining prices. OPEC also pursued a price-targeting policy in the decade 2004-2014, to maintain a relatively tight market balance and quotations elevated, while after the crisis it acted to push up quotations ahead of the economic recovery. Two thirds of the price drop between the end of 2014 and early 2016 is attributed to OPEC's market-share targeting strategy and in the first six months the drop is fully explained by supply factors. The opposite move, tightening up global supply to trigger the de-stocking of oil inventories overhung, contributed to the recovery since the end of 2016.

As a complementary result, we obtain separate estimates for OPEC and non-OPEC supply elasticities. In line with Caldara, Cavallo, and Iacoviello (2019), we find that the price elasticity of the OPEC supply curve is larger than that of the non-OPEC supply curve, an indirect confirmation of the fact that large spare capacity gives OPEC a greater ability to adjust production also following strategic considerations. 


\section{Appendices}

\subsection{Step by step model derivation}

We hold two assumptions in the following derivation: linearity of the demand schedule (see equation 2) and increasing marginal cost of production for non-OPEC $\alpha=\delta Q_{N O}$. From section 2 we can compute non-OPEC equilibrium production under the status quo $\frac{a+c}{b+\delta b c}$ and OPEC production $\frac{c}{b} * \frac{\delta(a-c)-b}{b+2 c \delta}$. As non-OPEC competitors produce as long as their cost remains below the price and they are price-takers, the equilibrium is simply pinned down as follows:

$$
\begin{array}{r}
p^{\prime}=\delta c Q_{N O}^{\prime} \\
\delta c Q_{N O}^{\prime}=a-b\left[Q_{O}+Q_{N O}+\Delta Q_{O}+\Delta Q_{N O}\right] \\
\delta c\left[Q_{N O}+\Delta Q_{N O}\right]=a-b\left[Q_{O}+Q_{N O}+\Delta Q_{O}+\Delta Q_{N O}\right] \\
p^{0}+\delta c \Delta Q_{N O}=p^{0}-b\left[\Delta Q_{O}+\Delta Q_{N O}\right] \\
\frac{\Delta Q_{N O}}{\Delta Q_{O}}=\frac{-b}{b+c \delta}
\end{array}
$$

Equation 15 holds irrespective of OPEC's strategy. Because non-OPEC faces increasing production costs, it will only partially offset changes in production coming from OPEC. This feature enables OPEC to move the equilibrium price by steering their supply.

\subsubsection{Price and Market Share targeting optimality condition}

Below we report step by step the derivation of optimality conditions for PT strategy to be pursued.

$$
\begin{array}{r}
\Pi_{P T}>\Pi_{0} \\
\left(p_{P T}-c\right)\left[Q_{O}-\Delta Q_{O}\right]>\left(p_{0}-c\right) Q_{O} \\
\left.\left(p_{P T}-p_{0}\right)\left[Q_{O}-\Delta Q_{O}\right]>\left(p_{0}-c\right) \Delta Q_{O}\right] \\
\Delta p_{P T}>(\alpha-1) c \frac{\Delta Q_{O}}{Q_{O}-\Delta Q_{O}} \\
b\left(\Delta Q_{N O}+\Delta Q_{O}\right)>(\alpha-1) c \frac{\Delta Q_{O}}{Q_{O}-\Delta Q_{O}} \\
\Delta Q_{O} \frac{\delta b c}{b+\delta c}>(\alpha-1) c \frac{\Delta Q_{O}}{\left[Q_{O}-\Delta Q_{O}\right.}
\end{array}
$$




$$
\begin{array}{r}
Q_{O}-\Delta Q_{O}>(\alpha-1) c \frac{b+\delta c}{b \delta c} \\
\frac{\Delta Q_{O}}{Q_{O}}<1-\frac{\left(\delta Q_{N O}-1\right)}{Q_{O}} \frac{b+\delta c}{b \delta} \\
\frac{\Delta Q_{O}}{Q_{O}}<1-\left(\frac{\delta(a+c)-2 \delta c-b}{c(\delta(a-c)-b)}\right) \frac{b+\delta c}{\delta} \\
\frac{\Delta Q_{O}}{Q_{O}}<1-\frac{b+\delta c}{\delta c} \\
\frac{\Delta Q_{O}}{Q_{O}}<\frac{-b}{\delta c}
\end{array}
$$

Similarly, a deviation from the status quo, consisting in increasing production above the equilibrium level by $\Delta Q_{O}$, is preferred by OPEC in order to regain market shares when $\Pi_{M S T}>\Pi_{0}$.

$$
\begin{array}{r}
\Delta p_{M S T}>(\alpha-1) c \frac{\Delta Q_{O}}{Q_{O}+\Delta Q_{O}} \\
\left.1+\frac{\Delta Q_{O}}{Q_{O}}>\frac{\delta(a+c)-2 \delta c-b}{c(\delta(a-c)-b)}\right) \frac{b+\delta c}{\delta} \\
\frac{\Delta Q_{O}}{Q_{O}}<\frac{b+\delta c}{\delta c}-1 \\
\frac{\Delta Q_{O}}{Q_{O}}>\frac{b}{\delta c}
\end{array}
$$

Therefore for $\frac{-b}{\delta c}<\frac{\Delta Q_{O}}{Q_{O}}<\frac{b}{\delta c}$ the status quo (acting as monopolist on the residual demand) stay preffered by OPEC.

\subsubsection{When is Price Targeting preferred to Market Share targeting ?}

We have identified a range of parameters under which each strategy is preferred to the status quo of playing monopolistic on the residual demand curve. But when is one of the two preferred in term of profits?

$$
\begin{array}{r}
\Pi_{P T}>\Pi_{M S T}\left(p_{P T}-c\right)\left[Q_{O}-\Delta Q_{O}\right]>\left(p_{M S T}-c\right)\left[Q_{O}+\Delta Q_{O}\right] \\
\left(p_{0}+\frac{\delta b c \Delta Q_{O}}{b+\delta c}-c\right)\left[Q_{O}-\Delta Q_{O}\right]>\left(p_{0}-\frac{\delta b c \Delta Q_{O}}{b+\delta c}-c\right)\left[Q_{O}+\Delta Q_{O}\right] \\
\frac{2 \delta b c \Delta Q_{O} Q_{O}}{b+\delta c}+2 c \Delta Q_{O}>2 p_{0} \Delta Q_{O} \\
Q_{O}>\left(p_{0}-c\right) \frac{b+\delta c}{\delta b c} \\
\frac{Q_{O}}{Q_{N O}}>\left(\delta c-\frac{c}{\frac{b+\delta b c}{a+c}}\right) \frac{b+\delta c}{\delta b c} \\
\frac{Q_{O}}{Q_{N O}}>\left(\delta-\frac{a+c}{b+\delta b c}\right) \frac{b+\delta c}{\delta b c}
\end{array}
$$

Therefore Price Targeting is preferred to Market Share Targeting as long as OPEC production remains above a precise threshold. 


\subsection{Appendix B Well behaved impulse response functions}

The IRF analysis is consistent with the results obtained from the historical decomposition of oil prices.

In line with sign restrictions, supply shocks, occurring when market-share is targeted, reduce total production on impact, leading to persistent higher oil prices and to a fall in economic activity for over a year. Unsurprisingly, every time a supply shock occurs when a desired price is targeted, the OPEC tends to counteract it; so doing it generates an offsetting effect on the real prices of oil and the real economic activity which therefore remain overall rather unaffected.

The response of the real price of oil to a demand shock and to precautionary demand follows similar dynamics in the 3 and the 4 shocks model. As expected, it raises production on impact and oil prices in a persistent way; however in our model price reaction to speculative shocks is shorter lived and it falls back to zero after 7 instead of the 10 months of the 3 -shocks model.

Finally, to make sure that the four shocks are correctly identified in our model, we rule out the possibility that the fifth unrestricted shock is anyhow correlated to the four identified shocks or that it affects sensibly the variables in the models. From the impulse response of the real price of oil, the global demand, the inventories and both OPEC and non-OPEC production, it is evident that the residual shocks have almost no impact on the variables considered in the model; the IRFs remain flat and insignificant at any time horizon.

Figure 10: The impulse response functions
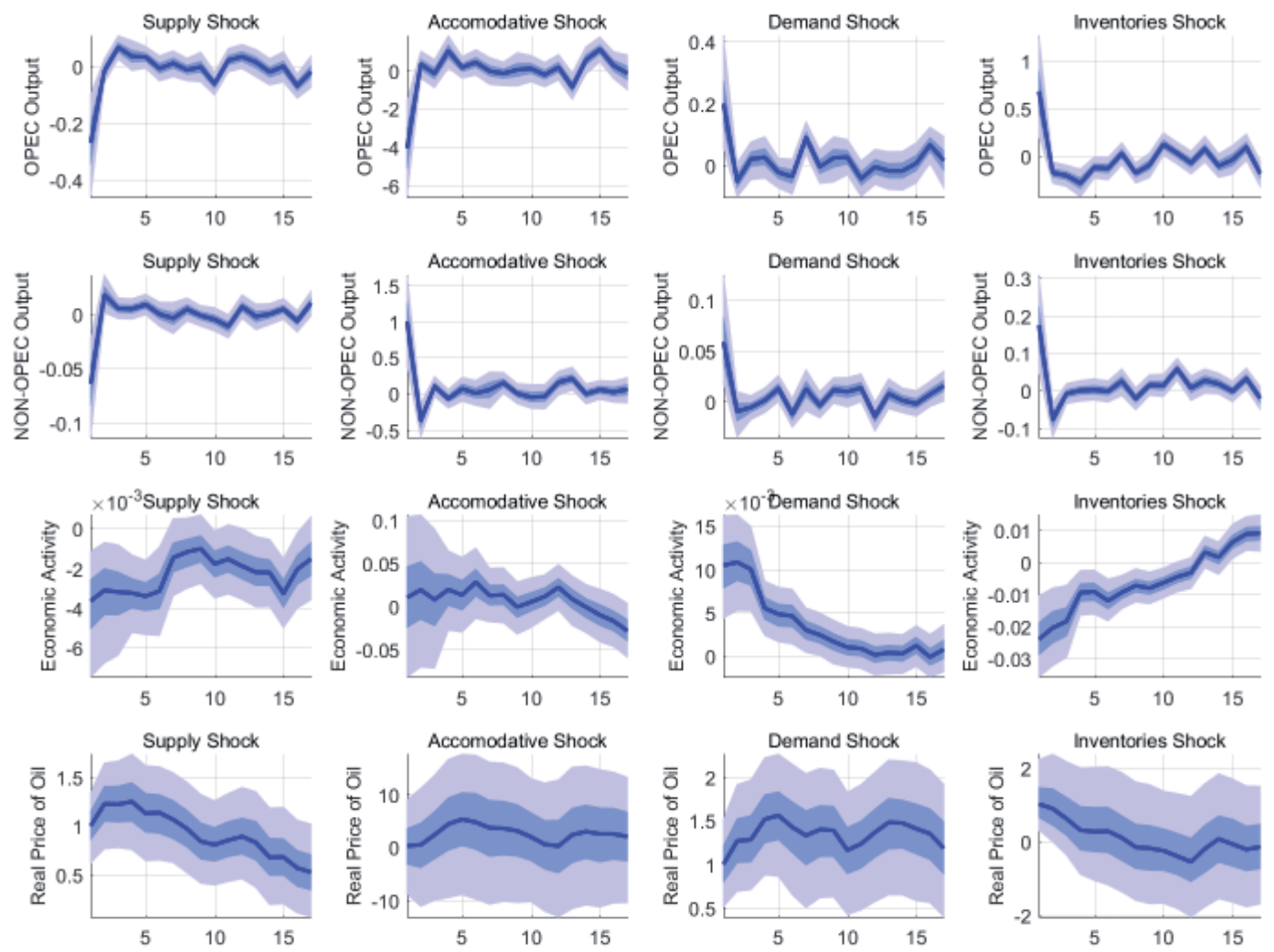


\section{References}

Arias, J., J. Rubio-Ramirez, and D. Waggoner (2018): "Inference Based on Structural Vector Autoregressions Identified With Sign and Zero Restrictions: Theory and Applications," Econometrica, 86(6), 685-720.

Baumeister, C., And J. D. Hamilton (2015): "Sign restrictions, structural vector autoregressions, and useful prior information," Econometrica, 83(5), 1963-1999.

(2019): "Structural interpretation of vector autoregressions with incomplete identification: Revisiting the role of oil supply and demand shocks," American Economic Review, 109(5), 18731910.

Baumeister, C., and G. Peersman (2013): "The role of time-varying price elasticities in accounting for volatility changes in the crude oil market," Journal of Applied Econometrics, 28(7), 1087-1109.

Behar, A., And R. A. Ritz (2017): "OPEC vs US shale: Analyzing the shift to a market-share strategy," Energy Economics, 63, 185-198.

Berg, E., S. Kverndokk, And K. E. Rosendahl (1997): "Market power, international CO taxation and oil wealth," The Energy Journal, pp. 33-71.

Caldara, D., M. Cavallo, and M. Iacoviello (2019): "Oil price elasticities and oil price fluctuations," Journal of Monetary Economics, 103, 1-20.

Chari, V. V., and L. Christiano (2017): "Financialization in commodity markets," Discussion paper.

DAhl, C. A. (2004): International Energy Markets: Understanding Pricing, Policies and Profits. Tulsa, OK, Pennwell.

Degiannakis, S., G. Filis, and V. Arora (2018): "Oil Prices and Stock Markets: A Review of the Theory and Empirical Evidence.," Energy Journal, 39(5).

Fattouh, B., and L. Mahadeva (2013): "OPEC: What Difference Has It Made?," Annu. Rev. Resour. Econ., 5(1), 427-443.

Foroni, C., And L. Stracca (2019): "Much ado about nothing? The shale oil revolution and the global supply curve," .

Gelman, M., Y. Gorodnichenko, S. Kariv, D. Koustas, M. D. Shapiro, D. Silverman, And S. TAdelis (2016): "The Response of Consumer Spending to Changes in Gasoline Prices," Discussion paper, National Bureau of Economic Research. 
Geroski, P. A., A. M. Ulph, and D. T. Ulph (1987): "A model of the crude oil market in which market conduct varies," The Economic Journal, 97, 77-86.

Giraitis, L., G. Kapetanios, and T. Yates (2018): "Inference on Multivariate Heteroscedastic Time Varying Random Coefficient Models," Journal of Time Series Analysis, 39(2), 129-149.

Golombek, R., A. A. Irarrazabal, and L. Ma (2018): "OPEC's market power: An empirical dominant firm model for the oil market," Energy Economics, 70, 98-115.

Hamilton, J. D. (2009): "Causes and Consequences of the Oil Shock of 2007-08," Discussion paper, National Bureau of Economic Research.

(2011): "Historical oil shocks," Discussion paper, National Bureau of Economic Research.

Hansen, P. V., and L. Lindholt (2008): "The market power of OPEC 1973-2001," Applied Economics, 40(22), 2939-2959.

Hausman, J. A., And W. K. Newey (1995): "Nonparametric estimation of exact consumers surplus and deadweight loss," Econometrica: Journal of the Econometric Society, pp. 1445-1476.

Huppmann, D., And F. Holz (2012a): "Crude oil market power-A shift in recent years?," The Energy Journal, 33(4), 1.

(2012b): "Crude Oil Market PowerA Shift in Recent Years?," The Energy Journal, 33(Number $4)$.

Juvenal, L., And I. Petrella (2015): "Speculation in the oil market," Journal of Applied Econometrics, 30(4), 621-649.

KiLIAN, L. (2008): "Exogenous oil supply shocks: how big are they and how much do they matter for the US economy?," The Review of Economics and Statistics, 90(2), 216-240.

(2009): "Not all oil price shocks are alike: Disentangling demand and supply shocks in the crude oil market," American Economic Review, 99(3), 1053-69.

(2017): "The impact of the fracking boom on Arab oil producers," The Energy Journal, $38(6)$.

Kilian, L., And D. P. MurPhy (2012): "Why agnostic sign restrictions are not enough: understanding the dynamics of oil market VAR models," Journal of the European Economic Association, 10(5), 1166-1188. 
(2014): "The role of inventories and speculative trading in the global market for crude oil," Journal of Applied Econometrics, 29(3), 454-478.

NAkov, A., And G. Nuno (2013): "Saudi Arabia and the oil market," The Economic Journal, 123(573), 1333-1362.

Peersman, G., C. Baumeister, et Al. (2009): "Time-Varying Effects of Oil Supply Shocks on the US Economy," in 2009 Meeting Papers, no. 171. Society for Economic Dynamics. 


\section{BANCO DE ESPAÑA PUBLICATIONS}

\section{WORKING PAPERS}

1910 JAMES COSTAIN, ANTON NAKOV and BORJA PETIT: Monetary policy implications of state-dependent prices and wages.

1911 JAMES CLOYNE, CLODOMIRO FERREIRA, MAREN FROEMEL and PAOLO SURICO: Monetary policy, corporate finance and investment.

1912 CHRISTIAN CASTRO and JORGE E. GALÁN: Drivers of productivity in the Spanish banking sector: recent evidence.

1913 SUSANA PÁRRAGA RODRÍGUEZ: The effects of pension-related policies on household spending.

1914 MÁXIMO CAMACHO, MARÍA DOLORES GADEA and ANA GÓMEZ LOSCOS: A new approach to dating the reference cycle.

1915 LAURA HOSPIDO, LUC LAEVEN and ANA LAMO: The gender promotion gap: evidence from Central Banking.

1916 PABLO AGUILAR, STEPHAN FAHR, EDDIE GERBA and SAMUEL HURTADO: Quest for robust optimal macroprudential policy.

1917 CARMEN BROTO and MATÍAS LAMAS: Is market liquidity less resilient after the financial crisis? Evidence for US treasuries.

1918 LAURA HOSPIDO and CARLOS SANZ: Gender Gaps in the Evaluation of Research: Evidence from Submissions to Economics Conferences.

1919 SAKI BIGIO, GALO NUÑO and JUAN PASSADORE: A framework for debt-maturity management.

1920 LUIS J. ÁLVAREZ, MARÍA DOLORES GADEA and ANA GÓMEZ-LOSCOS: Inflation interdependence in advanced economies.

1921 DIEGO BODAS, JUAN R. GARCÍA LÓPEZ, JUAN MURILLO ARIAS, MATÍAS J. PACCE, TOMASA RODRIGO LÓPEZ, JUAN DE DIOS ROMERO PALOP, PEP RUIZ DE AGUIRRE, CAMILO A. ULLOA and HERIBERT VALERO LAPAZ: Measuring retail trade using card transactional data.

1922 MARIO ALLOZA and CARLOS SANZ: Jobs multipliers: evidence from a large fiscal stimulus in Spain.

1923 KATARZYNA BUDNIK, MASSIMILIANO AFFINITO, GAIA BARBIC, SAIFFEDINE BEN HADJ, ÉDOUARD CHRÉTIEN, HANS DEWACHTER, CLARA ISABEL GONZÁLEZ, JENNY HU, LAURI JANTUNEN, RAMONA JIMBOREAN, OTSO MANNINEN, RICARDO MARTINHO, JAVIER MENCÍA, ELENA MOUSARRI, LAURYNAS NARUŠEVIČIUS, GIULIO NICOLETTI, MICHAEL O'GRADY, SELCUK OZSAHIN, ANA REGINA PEREIRA, JAIRO RIVERA-ROZO, CONSTANTINOS TRIKOUPIS, FABRIZIO VENDITTI and SOFÍA VELASCO: The benefits and costs of adjusting bank capitalisation: evidence from Euro Area countries.

1924 MIGUEL ALMUNIA and DAVID LÓPEZ-RODRÍGUEZ: The elasticity of taxable income in Spain: 1999-2014.

1925 DANILO LEIVA-LEON and LORENZO DUCTOR: Fluctuations in global macro volatility.

1926 JEF BOECKX, MAARTEN DOSSCHE, ALESSANDRO GALESI, BORIS HOFMANN and GERT PEERSMAN: Do SVARs with sign restrictions not identify unconventional monetary policy shocks?

1927 DANIEL DEJUÁN and JUAN S. MORA-SANGUINETTI: Quality of enforcement and investment decisions. Firm-level evidence from Spain.

1928 MARIO IZQUIERDO, ENRIQUE MORAL-BENITO and ELVIRA PRADES: Propagation of sector-specific shocks within Spain and other countries.

1929 MIGUEL CASARES, LUCA DEIDDA and JOSÉ E. GALDÓN-SÁNCHEZ: On financial frictions and firm market power.

1930 MICHAEL FUNKE, DANILO LEIVA-LEON and ANDREW TSANG: Mapping China's time-varying house price landscape.

1931 JORGE E. GALÁN and MATÍAS LAMAS: Beyond the LTV ratio: new macroprudential lessons from Spain.

1932 JACOPO TIMINI: Staying dry on Spanish wine: the rejection of the 1905 Spanish-Italian trade agreement.

1933 TERESA SASTRE and LAURA HERAS RECUERO: Domestic and foreign investment in advanced economies. The role of industry integration.

1934 DANILO LEIVA-LEON, JAIME MARTÍNEZ-MARTÍN and EVA ORTEGA: Exchange rate shocks and inflation comovement in the euro area.

1935 FEDERICO TAGLIATI: Child labor under cash and in-kind transfers: evidence from rural Mexico.

1936 ALBERTO FUERTES: External adjustment with a common currency: the case of the euro area.

1937 LAURA HERAS RECUERO and ROBERTO PASCUAL GONZÁLEZ: Economic growth, institutional quality and financial development in middle-income countries.

1938 SILVIA ALBRIZIO, SANGYUP CHOI, DAVIDE FURCERI and CHANSIK YOON: International Bank Lending Channel of Monetary Policy.

1939 MAR DELGADO-TÉLLEZ, ENRIQUE MORAL-BENITO and JAVIER J. PÉREZ: Outsourcing and public expenditure: an aggregate perspective with regional data. 
1940 MYROSLAV PIDKUYKO: Heterogeneous spillovers of housing credit policy.

1941 LAURA ÁLVAREZ ROMÁN and MIGUEL GARCÍA-POSADA GÓMEZ: Modelling regional housing prices in Spain.

1942 STÉPHANE DÉES and ALESSANDRO GALESI: The Global Financial Cycle and US monetary policy in an interconnected world.

1943 ANDRÉS EROSA and BEATRIZ GONZÁLEZ: Taxation and the life cycle of firms.

1944 MARIO ALLOZA, JESÚS GONZALO and CARLOS SANZ: Dynamic effects of persistent shocks.

1945 PABLO DE ANDRÉS, RICARDO GIMENO and RUTH MATEOS DE CABO: The gender gap in bank credit access.

1946 IRMA ALONSO and LUIS MOLINA: The SHERLOC: an EWS-based index of vulnerability for emerging economies.

1947 GERGELY GANICS, BARBARA ROSSI and TATEVIK SEKHPOSYAN: From Fixed-event to Fixed-horizon Density Forecasts: Obtaining Measures of Multi-horizon Uncertainty from Survey Density Forecasts.

1948 GERGELY GANICS and FLORENS ODENDAHL: Bayesian VAR Forecasts, Survey Information and Structural Change in the Euro Area.

2001 JAVIER ANDRÉS, PABLO BURRIEL and WENYI SHEN: Debt sustainability and fiscal space in a heterogeneous Monetary Union: normal times vs the zero lower bound.

2002 JUAN S. MORA-SANGUINETTI and RICARDO PÉREZ-VALLS: ¿Cómo afecta la complejidad de la regulación a la demografía empresarial? Evidencia para España.

2003 ALEJANDRO BUESA, FRANCISCO JAVIER POBLACIÓN GARCÍA and JAVIER TARANCÓN: Measuring the procyclicality of impairment accounting regimes: a comparison between IFRS 9 and US GAAP.

2004 HENRIQUE S. BASSO and JUAN F. JIMENO: From secular stagnation to robocalypse? Implications of demographic and technological changes.

2005 LEONARDO GAMBACORTA, SERGIO MAYORDOMO and JOSÉ MARÍA SERENA: Dollar borrowing, firm-characteristics, and FX-hedged funding opportunities.

2006 IRMA ALONSO ÁLVAREZ, VIRGINIA DI NINO and FABRIZIO VENDITTI: Strategic interactions and price dynamics in the global oil market.

\section{BANCODEESPAÑA}

Eurosistema
Unidad de Servicios Generales I

Alcalá, 48 - 28014 Madrid

E-mail: publicaciones@bde.es www.bde.es 